\title{
High variability of the heterogeneous ice nucleation potential of oxalic acid dihydrate and sodium oxalate
}

\author{
R. Wagner, O. Möhler, H. Saathoff, M. Schnaiter, and T. Leisner \\ Karlsruhe Institute of Technology, Institute for Meteorology and Climate Research, Karlsruhe, Germany \\ Received: 21 April 2010 - Published in Atmos. Chem. Phys. Discuss.: 28 April 2010 \\ Revised: 2 August 2010 - Accepted: 11 August 2010 - Published: 16 August 2010
}

\begin{abstract}
The heterogeneous ice nucleation potential of airborne oxalic acid dihydrate and sodium oxalate particles in the deposition and condensation mode has been investigated by controlled expansion cooling cycles in the AIDA aerosol and cloud chamber of the Karlsruhe Institute of Technology at temperatures between 244 and $228 \mathrm{~K}$. Previous laboratory studies have highlighted the particular role of oxalic acid dihydrate as the only species amongst a variety of other investigated dicarboxylic acids to be capable of acting as a heterogeneous ice nucleus in both the deposition and immersion mode. We could confirm a high deposition mode ice activity for 0.03 to $0.8 \mu \mathrm{m}$ sized oxalic acid dihydrate particles that were either formed by nucleation from a gaseous oxalic acid/air mixture or by rapid crystallisation of highly supersaturated aqueous oxalic acid solution droplets. The critical saturation ratio with respect to ice required for deposition nucleation was found to be less than 1.1 and the size-dependent ice-active fraction of the aerosol population was in the range from 0.1 to $22 \%$. In contrast, oxalic acid dihydrate particles that had crystallised from less supersaturated solution droplets and had been allowed to slowly grow in a supersaturated environment from still unfrozen oxalic acid solution droplets over a time period of several hours were found to be much poorer heterogeneous ice nuclei. We speculate that under these conditions a crystal surface structure with less-active sites for the initiation of ice nucleation was generated. Such particles partially proved to be almost ice-inactive in both the deposition and condensation mode. At times, the heterogeneous ice nucleation ability of oxalic acid dihydrate significantly changed when the particles had been processed in preceding cloud droplet activation steps. Such behaviour was also observed for the second investi-
\end{abstract}

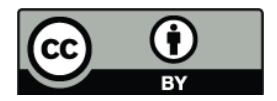

Correspondence to: R. Wagner (robert.wagner2@kit.edu) gated species, namely sodium oxalate. Our experiments address the atmospheric scenario that coating layers of oxalic acid or its salts may be formed by physical and chemical processing on pre-existing particulates such as mineral dust and soot. Given the broad diversity of the observed heterogeneous ice nucleability of the oxalate species, it is not straightforward to predict whether an oxalate coating layer will improve or reduce the ice nucleation ability of the seed aerosol particles.

\section{Introduction}

Several recent studies have addressed the hygroscopic behaviour (deliquescence and efflorescence phase transitions) and ice nucleation abilities of low molecular weight dicarboxylic acids (Braban et al., 2003; Kanji et al., 2008; Mikhailov et al., 2009; Parsons et al., 2004; Peng et al., 2001; Prenni et al., 2001; Shilling et al., 2006; Treuel et al., 2008; Zobrist et al., 2006). These compounds have been identified as an important contribution to the water-soluble organic fraction of the tropospheric aerosol, typically comprising 1 $3 \%$ of the total particulate organic carbon in urban and semiurban areas and up to $10 \%$ in remote continental and marine environments (Carlton et al., 2007; Chebbi and Carlier, 1996; Crahan et al., 2004; Ervens et al., 2004; Hsieh et al., 2007; Kawamura et al., 1996; Kerminen et al., 2000; Kerminen et al., 1999; Limbeck et al., 2005; Yao et al., 2002). Their presence in the atmosphere is ascribed to both primary emissions and various secondary formation pathways, amongst which photo-oxidations of gaseous organic precursors and subsequent gas-to-particle conversion, heterogeneous reactions on particle surfaces, as well as aqueous in-cloud reaction mechanisms are currently discussed (Yang et al., 2009). In most

Published by Copernicus Publications on behalf of the European Geosciences Union. 
cases, oxalic acid (C2) is found to be the most abundant species, followed by malonic (C3) and succinic acid (C4).

In the following, we will give a brief literature survey on the hygroscopic properties of oxalic acid, starting with the aerosol flow tube/FTIR study by Braban et al. (2003). The authors have generated a polydisperse aerosol of anhydrous oxalic acid particles by spray-drying of an aqueous solution at a relative humidity (RH) of less than 5\%. As apparent from the recorded infrared spectrum, the chain-like $\beta$ form of anhydrous oxalic acid has formed where the molecules are linked together in pairs by cyclic hydrogen bonds (Bellamy and Pace, 1963; Villepin and Novak, 1978a; Villepin and Novak, 1978b). Upon increasing relative humidity, two phase transitions were observed: from anhydrous $\beta$ oxalic acid to oxalic acid dihydrate at 9-21\% RH (294-259 K) and the deliquescence transition to an aqueous solution at 97 99\% RH (294-279 K). The structure of oxalic acid dihydrate is similar to that of the anhydrous $\beta$ form, with two water molecules included between the carboxyl groups. Its infrared spectrum is characterised by a prominent doublet feature at around $3500 \mathrm{~cm}^{-1}$ due to the hydration water whereas aqueous oxalic acid solution droplets reveal a broader and less-structured absorption band in the $\mathrm{O}-\mathrm{H}$ stretching regime. Note that two polymorphs of oxalic acid dihydrate have only been observed for the completely deuterated form (Ebisuzaki and Angel, 1981). According to Braban et al. (2003), it was difficult to effloresce oxalic acid aerosol particles. In a number of experiments the aerosol water was not completely removed by the drier, leaving behind an aerosol that featured a continuous water uptake over the complete RH range. Such behaviour was also observed in two independent H-TDMA (hygroscopicity tandem differential mobility analyser) investigations (Mikhailov et al., 2009; Prenni et al., 2001).

Prenni et al. (2001) have measured the hygroscopic growth curve of size selected, 50 and $100 \mathrm{~nm}$ diameter oxalic acid particles generated by spray-drying at $<5 \% \mathrm{RH}(303 \mathrm{~K})$. As already indicated, a continuous water uptake between 45 and 91\% RH was detected which could be explained by the presence of concentrated solution droplets instead of effloresced particles. An overall similar growth curve was recently measured by Mikhailov et al. (2009) from $<5$ to $95 \%$ RH for a monodispersed $100 \mathrm{~nm}$ diameter oxalic acid aerosol at ambient temperature, generated by nebulisation of an aqueous solution, drying at $\mathrm{RH}<5 \%$, and size selecting the $100 \mathrm{~nm}$ dry particle diameter by a differential mobility analyser. A closer inspection of the growth curve, however, revealed some trends and small-scale fluctuations that are inconsistent with the assumption that liquid-like aerosol particles were present: (i) a decrease of the growth factor in the range from 5 to $40 \%$ RH, (ii), a small, stepwise increase in the growth factor at about $43 \% \mathrm{RH}$, going along with a sudden broadening of the mode width of the measured size distribution, and, (iii), small-scale fluctuations in the growth curve until reaching a relative humidity of $80 \%$. As an explanation, the authors proposed that spray-drying of the solution droplets had led to the formation of amorphous, highly porous oxalic acid particles with a gel-like structure. The discontinuities in the growth curve could then be attributed to microstructural rearrangements and transitions between collapsed and swollen gel structures. Only above a relative humidity of $80 \%$, the close agreement between the mode widths of the particle size distribution in repetitive hydration and dehydration experiments points to the presence of fully deliquesced liquid aqueous solution droplets.

Complementing the contradictory results on the hygroscopic behaviour of oxalic acid particles, Peng et al. (2001) have detected an efflorescence transition in 10-20 $\mu \mathrm{m}$ sized oxalic acid particles at $52-57 \% \mathrm{RH}$. The particles were levitated in an electrodynamic balance at $298 \mathrm{~K}$. No further change in the particle mass was detected when lowering the relative humidity to $5 \%$. The latter was chosen as a reference state for water-free particles, implying that the efflorescence transition had directly led to the crystallisation of anhydrous oxalic acid particles. As suggested by Mikhailov et al. (2009), the inconsistent findings could partly be explained by size effects when assuming that a part of the polydisperse aerosol in the Braban et al. (2003) study had also extended into the $>1 \mu \mathrm{m}$ size range and that this tail of the size distribution had then dominated the mass fraction and been responsible for the overall infrared spectral signature. In this way, one could combine the results from Braban et al. (2003) and Peng et al. (2001) for super-micron sized particles where crystallisation of oxalic acid is obviously facilitated whereas the findings from Prenni et al. (2001) and Mikhailov et al. (2009) for $\leq 100 \mathrm{~nm}$ particles suggest the predominant formation of (semi-)solid amorphous particles.

Prenni et al. (2001) have probed size-selected 50 and $100 \mathrm{~nm}$ diameter oxalic acid particles, generated in the same way as for their H-TDMA measurements, also in a continuous flow diffusion chamber (CFDC) to measure ice formation. As discussed above, these particles were supposedly either concentrated solution droplets, or, according to the interpretation from Mikhailov et al. (2009), gel-like amorphous particles. The threshold ice relative humidity to freeze $1 \%$ of those particles at temperatures between about 228 and $217 \mathrm{~K}$ almost coincided with water saturation, making them less efficient ice nuclei in comparison with supercooled inorganic aqueous solution droplets like sulphuric acid and ammonium sulphate. Several further studies have addressed the ice nucleation potential of pure dicarboxylic acids. Kanji et al. (2008) have investigated the ice formation via deposition nucleation on oxalic acid dihydrate particles deposited on a Teflon-coated, copper cold stage at $233 \mathrm{~K}$. The particles were prepared from a dilute aqueous solution using an atomiser and, by inspection of the optical micrograph shown in Fig. 3 of their publication, covered a size range between about 1 and $8 \mu \mathrm{m}$ in diameter. Prior to an ice nucleation experiment, the deposited particles were dried at $\mathrm{RH}<1 \%(298 \mathrm{~K})$ for $18 \mathrm{~h}$, most probably leading to the formation of anhydrous oxalic acid. According to the results from Braban et al. (2003), 
these anhydrous particles should have transformed into oxalic acid dihydrate prior to ice nucleation due to the elevated humidity levels encountered in the course of the ice nucleation experiments. Kanji et al. (2008) have determined threshold relative humidities for the nucleation of a single ice particle on the ensemble of deposited particles as a function of the total particulate surface area. The surface area was varied by adjusting the total number of particles on the stage, typically from a few hundred to several $10^{5}$ particles (Kanji and Abbatt, 2006). The measured critical ice saturation ratios ranged from about 1.10-1.25 for total particulate surface areas in the range of $2 \times 10^{-1}-6 \times 10^{-4} \mathrm{~cm}^{2}$. The observed high ice nucleability in the deposition mode clearly contradicts the results from Prenni et al. (2001), indicating that the particles probed in the CFDC chamber were indeed not crystalline. Micrometer-sized, spray-deposited particles of maleic acid ( $\mathrm{C} 4$ unsaturated dicarboxylic acid) also proved to be efficient heterogeneous ice nuclei in the deposition mode at low temperatures (Shilling et al., 2006). Critical ice saturation ratios for nucleating ice on the maleic acid particles ranged from about 1.05 at $220 \mathrm{~K}$ to 1.30 at $190 \mathrm{~K}$. In contrast, Parsons et al. (2004) have reported that 2-40 $\mu \mathrm{m}$ sized particles of saturated C3-C6 dicarboxylic acids are not good ice nuclei in the deposition mode at temperatures above $243 \mathrm{~K}$. Instead of heterogeneously nucleating ice at temperatures below the eutectic temperature, i.e., at ice supersaturated conditions, these particles underwent a deliquescence transition to aqueous solution droplets. Oxalic acid (C2) has not been investigated.

Zobrist et al. (2006) specifically addressed the ability of several dicarboxylic acids as heterogeneous ice nuclei in the immersion mode, arguing that in most cases these substances would be part of a multi-component mixture in atmospheric aerosol particles. If precipitating from these mixtures, the organic crystals would therefore be included in an aqueous solution with other inorganic and/or organic solutes and thus could only act as immersion ice nuclei. The freezing experiments were performed with emulsified binary dicarboxylic acid/water solutions of different solute concentrations and selected ternary solutions with e.g. sulphuric acid, ammonium sulphate, and sodium chloride as additional solute species. Ice freezing temperatures were measured with a differential scanning calorimeter. The authors demonstrated that in several of the emulsified aqueous solutions (e.g. binary 5.0, 9.8, and $19.8 \mathrm{wt} \%$ oxalic acid, $7.3 \mathrm{wt} \%$ succinic acid, and $1.6 \mathrm{wt} \%$ adipic acid solutions) homogeneous ice nucleation had triggered the precipitation of the organic solute. Only in the case of oxalic acid, however, supposedly precipitated as oxalic acid dihydrate, these embedded crystals then acted as immersion mode ice nuclei in a second freezing cycle, as evidenced by a freezing temperature higher than the homogeneous freezing temperature of pure water. The study by Zobrist et al. (2006) has motivated the heterogeneous ice nucleation experiments with oxalic acid particles which we will present in this manuscript. Our first intention was to repro-

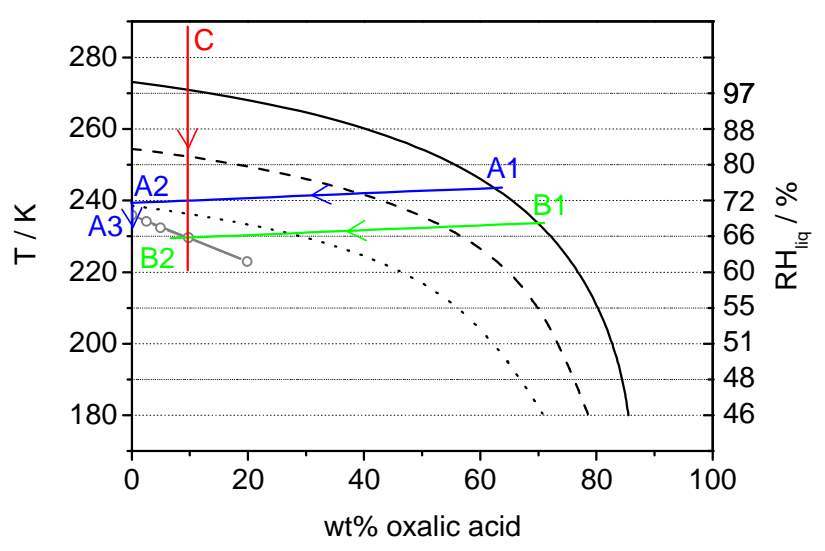

Fig. 1. Schematic experimental trajectories of various ice nucleation experiments with supercooled oxalic acid solution droplets in the oxalic acid-water phase diagram. The solid black line indicates the ice melting-point curve, as calculated for an ideal solution with Raoult's law. Although Raoult's law reasonably fits the measured water activities of aqueous oxalic acid at room temperature (Clegg and Seinfeld, 2006; Peng et al., 2001), its validity for low temperatures still has to be verified. Hence, the solid black trace possibly will only give a rough estimate of the solute concentration at icesaturated conditions. The right y-axis denotes the prevailing relative humidity with respect to supercooled water, $\mathrm{RH}_{\text {liq }}$, for an environment that is saturated with respect to ice, i.e., when moving on the ice-melting-point curve within the phase diagram. Two additional black traces denote the temperature-dependent oxalic acid concentrations that were calculated for ice saturation ratios of 1.2 (dashed line) and 1.4 (dotted line). The grey circles denote the critical homogeneous ice nucleation temperatures as a function of oxalic acid concentration from the study by Zobrist et al. (2006). The blue and green trajectories represent hypothetical expansion cooling experiments with airborne particles in the AIDA cloud chamber, whereas the red trajectory corresponds to a freezing experiment with emulsified oxalic acid solution droplets. See text for details.

duce the results from cooling cycles with emulsified solutions by controlled expansion cooling experiments with airborne particles, conducted in the large coolable aerosol and cloud chamber AIDA of the Karlsruhe Institute of Technology. In the following two paragraphs we briefly describe what should be observed in respective series of AIDA experiments on the basis of the results of Zobrist et al. (2006).

The experimental trajectory in the temperaturecomposition plane for ice nucleation experiments with airborne particles significantly differs from that with emulsified solutions (Fig. 1). In the latter case, the solute concentration remains constant during cooling (trace $\mathrm{C}$ ) and ice crystals formed by homogeneous nucleation in the first cooling cycle have to be melted by heating the solutions to a conditioning temperature above the eutectic temperature. Then another cooling cycle is started to probe the heterogeneous ice nucleation ability of the potentially precipitated organic crystals. The experimental trajectories of two 
conceivable AIDA expansion cooling cycles with binary oxalic acid/water solution droplets are schematically shown as green and blue traces in Fig. 1. Experiment A is started at an initial gas temperature of $244 \mathrm{~K}$, i.e., slightly above the homogeneous freezing temperature of pure water droplets at about $236 \mathrm{~K}$. The initial composition of the injected oxalic acid solution droplets adjusts to the prevailing relative humidity which is close to the saturation pressure over ice because the inner walls of the AIDA chamber are coated with a thin ice layer in the preparation of an expansion run, as outlined in detail in Sect. 2. Thereby, the initial composition is given by point $\mathrm{A} 1$ on the ice melting-point curve in aqueous oxalic acid solutions. As can be seen from the phase diagram, the aerosol consists of highly concentrated solution droplets with about $62 \mathrm{wt} \%$ oxalic acid. As a comparison, the saturation concentration of oxalic acid at $244 \mathrm{~K}$ is about $0.7 \mathrm{wt} \%$, based on a thermodynamic extrapolation of bulk solubilities measured at higher temperatures (Apelblat and Manzurola, 1987; Omar and Ulrich, 2006).

To initiate the ice freezing, the AIDA pressure is reduced by controlled pumping. Upon expansion cooling, the aerosol strongly dilutes due to the increasing relative humidity (see Sect. 2 for the experimental details). After about 3 to 4 degrees of cooling ( 240 to $241 \mathrm{~K}$, A2), the relative humidity with respect to supercooled water has increased from $75 \%$ (corresponding to an ice saturation ratio of one at $244 \mathrm{~K}$ ) to $100 \%$, leading to the activation of the oxalic acid solution droplets to a cloud of almost pure supercooled water droplets. This cloud eventually glaciates at point $\mathrm{A} 3$ when the gas temperature has further dropped below the homogeneous freezing temperature of pure water droplets. After completed glaciation, the pumping is stopped and the ice crystals slowly evaporate on a timescale of typically 15 to 20 min while the gas temperature gradually recuperates its original value. A second expansion cooling cycle with the same aerosol loading is then started again at $244 \mathrm{~K}$ to check whether the droplet freezing has also triggered the crystallisation of oxalic acid (dihydrate). The organic crystals could act as deposition mode ice nuclei at temperatures between 244 and $240-241 \mathrm{~K}$, or, once water saturation is reached, act as condensation freezing nuclei (a liquid layer condenses on the particles, which subsequently initiates the freezing) before reaching a temperature of $236 \mathrm{~K}$ provided that the crystals would not instantly and completely deliquesce on the timescale of the expansion cooling experiment. When conducting such an experiment with multi-component oxalic acid-containing solution droplets, only condensation freezing could take place. Experiment B (green trace) is started with a fresh aerosol loading at an initial gas temperature of $233 \mathrm{~K}$ (B1), i.e., below the homogeneous freezing temperature of pure water droplets. The injected oxalic acid droplets will homogeneously freeze in the first expansion cycle once the dilution has gone below a critical threshold value (B2) but they will not dilute to almost pure water droplets as in experiment A. In the second expansion cycle, the potentially precipitated oxalic acid (dihydrate) crystals could act as ice nuclei in the deposition mode, or, when conducting an experiment with a multi-component mixture, act as ice nuclei in the immersion mode, thereby potentially inducing earlier ice formation compared to the homogeneous freezing run.

This envisaged experimental approach has successfully been applied to ternary solution droplets with sulphuric acid and sodium chloride as additional solute species. We will report these results in a forthcoming manuscript. Concerning freezing experiments with binary oxalic acid/water solution droplets, we never observed that the injected aerosol particles remained in a supercooled liquid state at temperatures $\leq 244 \mathrm{~K}$. Instead, as proven by infrared extinction measurements, solid oxalic acid dihydrate crystallised from the highly supersaturated solution droplets. These particles revealed a remarkably high variability in their ice nucleation potential, depending on the way they were generated. When directly injecting aqueous oxalic acid solution droplets into the cooled AIDA chamber at e.g. $244 \mathrm{~K}$, the crystallisation of the entire particle ensemble to oxalic acid dihydrate took place on a time scale of about one hour. In another type of experiment, the droplet aerosol was added to the chamber at a higher temperature (e.g., $266 \mathrm{~K}$ ) and then slowly cooled to $244 \mathrm{~K}$, thereby causing a much slower overall crystallisation process. The spectrum of the ice nucleation ability of the variously generated oxalic acid dihydrate crystals at $244 \mathrm{~K}$ ranged from very efficient deposition mode ice nucleation, as also recently observed by Kanji et al. (2008), to almost ice inactivity. At times, distinctive changes in the ice nucleation ability were observed in consecutive expansion cooling cycles.

In the present manuscript, we summarise these results on the heterogeneous ice nucleation potential of oxalic acid dihydrate. As a second species, anhydrous sodium oxalate particles were also investigated. Albeit acknowledging the argumentation from Zobrist et al. (2006) that in most atmospheric particles oxalic acid (dihydrate) crystals, if present, will be embedded in a surrounding solution and thereby be unsusceptible for deposition mode ice nucleation, studies on pure oxalate particles remain of scientific interest. They form the basis for the interpretation of the experiments with the more complex, multi-component aerosol particles and underline that already pure, comparatively simply structured organic species may feature a complex, highly variable ice nucleation behaviour. In addition, as already indicated in the first paragraph, mechanisms are discussed that could lead to the formation of coating layers of oxalate species on pre-existing aerosol particles. Therefore, one cannot exclude that potentially precipitated oxalate crystals are directly exposed to an ice supersaturated environment and could also act as deposition mode ice nuclei. 


\section{Experimental}

A schematic view of the AIDA aerosol and cloud chamber facility, featuring the relevant instrumentation for the oxalic acid and sodium oxalate crystallisation and expansion cooling experiments, is shown in Fig. 2. The aerosol chamber, a $84.3 \mathrm{~m}^{3}$ sized aluminium vessel of $4 \mathrm{~m}$ diameter, is located inside an isolating containment whose interior can be cooled to temperatures as low as $183 \mathrm{~K}$. The spatial temperature fluctuations throughout the whole chamber interior, as measured by arrays of horizontally and vertically arranged temperature sensors, is less than $\pm 0.3 \mathrm{~K}$. The chamber can be evacuated with two vacuum pumps to a minimum pressure of less than $0.01 \mathrm{hPa}$. Repetitive evacuation and flushing cycles with particle-free synthetic air usually provide background particle number concentrations of less than $0.1 \mathrm{~cm}^{-3}$. In addition, the pressure control enables controlled expansion cooling experiments to establish ice supersaturated conditions in the chamber as a prerequisite for studying ice nucleation.

In the following, we will describe the various employed methods for aerosol generation and present typical number size distributions of the added aerosol particles. Thereafter, we will briefly summarise the operation of the AIDA vessel as a cloud expansion chamber and introduce the most important measurement devices, including in situ water vapour measurements by tuneable diode laser absorption spectroscopy as well as aerosol and cloud particle characterisation by optical particle counters, infrared extinction measurements, and laser light scattering and depolarisation measurements. For readers interested in more details, we recommend the publications by Benz et al. (2005) and Möhler et al. (2005) concerning the methodology of the expansion cooling cycles and the recent review by Wagner et al. (2009) on the optical measurements at the AIDA chamber. We will conclude this chapter with a tabular compilation of the experimental procedures for the various crystallisation and ice freezing experiments whose results will then be discussed in Sect. 3 .

Four different methods were used to generate oxalic acid and sodium oxalate aerosol particles of median diameters ranging from $30 \mathrm{~nm}$ to $0.8 \mu \mathrm{m}$. In most cases, the aerosol was generated from aqueous solutions of typically $4-8 \mathrm{wt} \%$ oxalic acid and $3 \mathrm{wt} \%$ sodium oxalate, prepared by dissolving crystalline oxalic acid dihydrate $\left((\mathrm{COOH})_{2} \cdot 2 \mathrm{H}_{2} \mathrm{O}\right.$, Merck, $\left.>99.5 \%, 126.07 \mathrm{~g} \mathrm{~mol}^{-1}\right)$ and sodium oxalate $\left(\mathrm{Na}_{2} \mathrm{C}_{2} \mathrm{O}_{4}\right.$, Merck, > 99.8\%, $134.01 \mathrm{~g} \mathrm{~mol}^{-1}$ ) in Milli-Q quality water. The solutions were subsequently filtrated by a submicron syringe filter (PTFE membrane) to remove any potentially remaining particulates. Depending on the prevailing AIDA temperature, the added solution droplets either initially remained in a supersaturated liquid state, or rapidly, at times instantly, crystallised to oxalic acid dihydrate and anhydrous sodium oxalate. The largest particles were obtained by ultrasonic nebulisation (URANUS, Sinaptec France), yielding

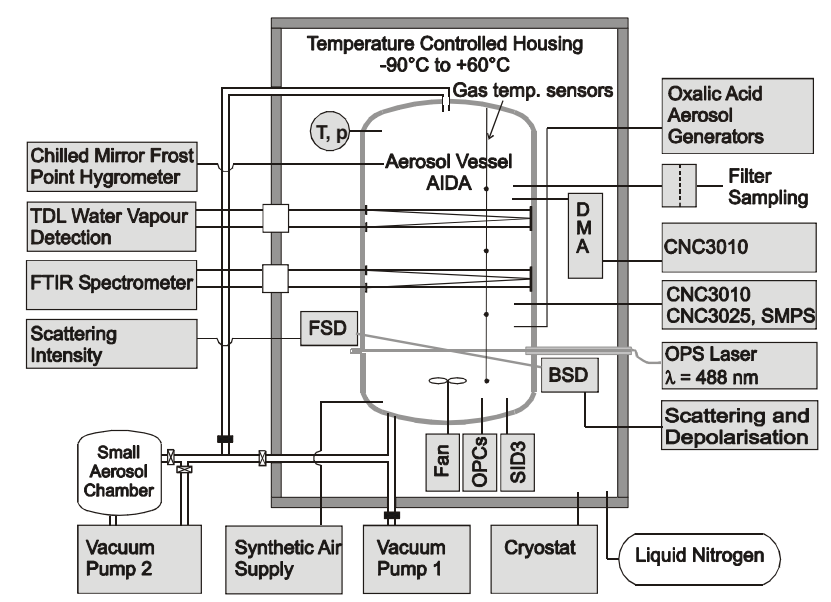

Fig. 2. Schematic cross section of the AIDA aerosol and cloud chamber facility, featuring the most important instrumentation for the crystallisation and ice nucleation experiments with oxalic acid dihydrate and sodium oxalate.

median diameters of about $0.55-0.80 \mu \mathrm{m}$. Panels a and $\mathrm{b}$ of Fig. 3 show typical number size distributions of solid oxalic acid dihydrate and sodium oxalate particles, as generated by rapid crystallisation after adding the aerosol to the AIDA chamber at $244 \mathrm{~K}$. The size distributions were measured with a scanning mobility particle sizer (SMPS, TSI) and an aerodynamic particle spectrometer (APS, TSI). Particles with median diameters of around $100 \mathrm{~nm}$ were generated with a compressed-air atomiser (TSI, model 3076). As an example, panel $\mathrm{c}$ of Fig. 3 shows the size distribution of solid oxalic acid dihydrate crystals, again obtained by rapid crystallisation after injection at $T=244 \mathrm{~K}$. For both the atomiser and ultrasonic nebuliser, an overall injection period of about 30 $60 \mathrm{~min}$ was required in order to obtain a sufficient mass loading for characterising the aerosol by long-path, in situ FTIR (Fourier transform infrared) extinction spectroscopy. Typical number concentrations ranged from $10000-20000 \mathrm{~cm}^{-3}$ when using the atomiser and $300-500 \mathrm{~cm}^{-3}$ for the ultrasonic nebuliser. In selected experiments, the aqueous solutions were directly sprayed into the cooled cloud chamber via a two-stream dispersion nozzle that was heated to about $293 \mathrm{~K}$. This proved to be a clean and efficient way to generate sufficient aerosol mass loadings within 5-10 s. Panel d of Fig. 3 shows an exemplary size distribution of initially supersaturated oxalic acid solution droplets obtained by spraying a $4 \mathrm{wt} \%$ oxalic acid solution into the AIDA chamber at $266 \mathrm{~K}$. As discussed in Sect. 3.3, the SMPS measurement is significantly biased in the case of supercooled solution droplets because the instrument is operated at a much lower relative humidity than prevalent in the AIDA chamber, inducing a shrinking of the particle size due to the loss of water. Finally, in a particular experiment nanometre-sized oxalic acid dihydrate crystallites were generated by passing synthetic 


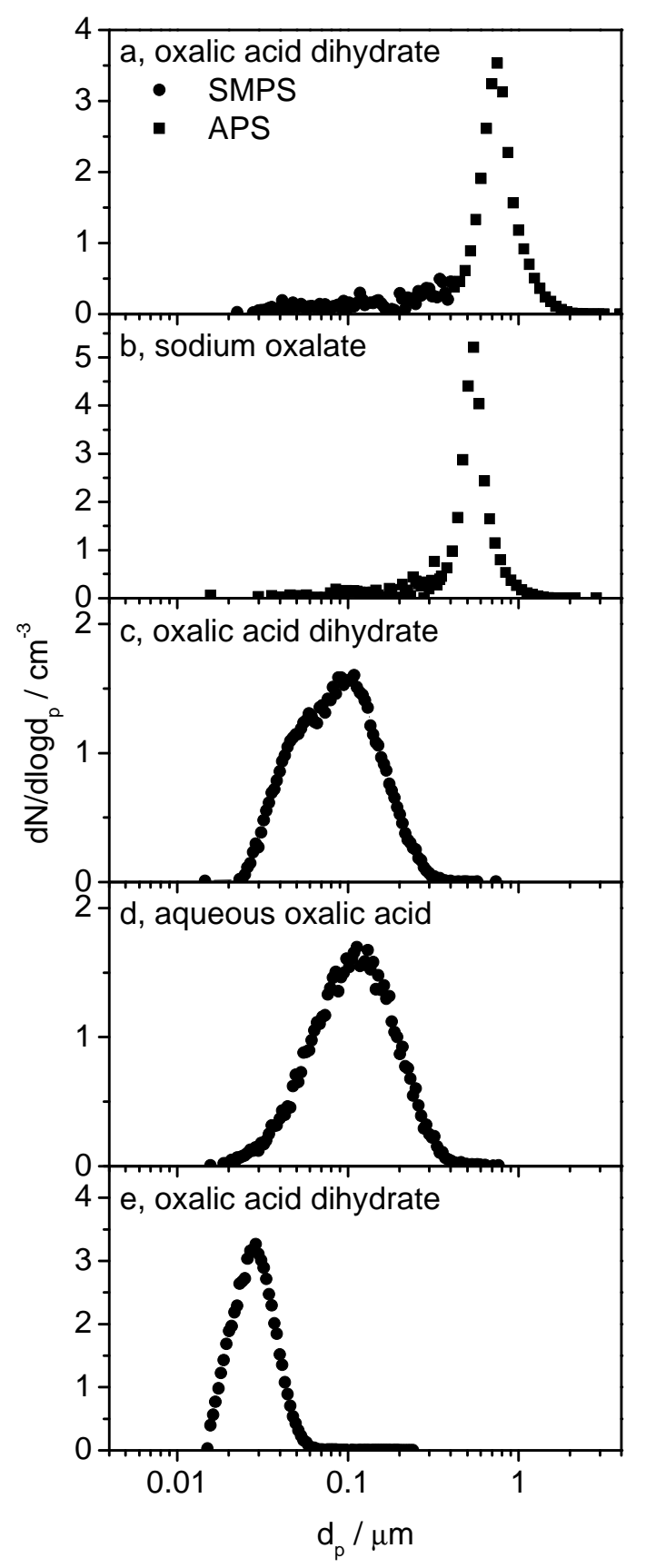

Fig. 3. Typical normalised SMPS and APS number size distributions of oxalate aerosols generated by various methods; see text for details. APS measurements were only done in cases (a) and (b) where a significant number fraction of the aerosol extended to diameters $>0.5 \mu \mathrm{m}$. The aerodynamic diameter of the APS was converted into a volume-equivalent sphere diameter $d_{p}$ assuming a particle density of $1.653 \mathrm{~g} \mathrm{~cm}^{-3}$ for oxalic acid dihydrate (a) and $2.34 \mathrm{~g} \mathrm{~cm}^{-3}$ for sodium oxalate (b). Due to the lack of appropriate shape information, the dynamic shape factor $\chi$ was set to 1.0 in both cases. When assuming spherical particles with $\chi=1$, the mobility-equivalent diameter of the SMPS would be equal to $d_{p}$ (Hinds, 1999; Hudson et al., 2007). air over a heated reservoir of crystalline oxalic acid dihydrate $(373 \mathrm{~K})$. The gaseous oxalic acid/air mixture was then directed via stainless steel connection tubes into the AIDA chamber that was held at $228 \mathrm{~K}$, thereby inducing the binary nucleation of oxalic acid and water. A total injection time of about $2 \mathrm{~h}$ was needed to positively identify oxalic acid dihydrate as the major outcome of this procedure by FTIR extinction measurements. As shown by panel e of Fig. 3, the median diameter of these crystallites was about $30 \mathrm{~nm}$.

In order to prepare the AIDA chamber for crystallisation experiments with succeeding expansion cooling cycles, the inner walls of the aluminium vessel are coated with a thin ice layer, typically made by evaporating a certain amount of Milli-Q quality water into the evacuated chamber at some higher temperature, refilling the chamber with particle-free synthetic air to ambient pressure, and subsequent cooling to a lower temperature. Due to some internal heat sources like heating foils, heated sampling tubes, and the mixing fan (see Fig. 2), the average gas temperature $T$ is typically $1{ }^{\circ} \mathrm{C}$ higher than the average wall temperature. As a result, the prevailing water vapour pressure $p_{w}(T)$ is slightly below the saturation pressure over ice $p_{w}$,ice $(T)$, yielding an ice saturation ratio $S_{\text {ice }}=p_{w}(T) / p_{w}$,ice $(T)$ of about $0.90-0.95$ at static pressure and temperature conditions prior to the expansion cooling cycle. With the onset of pumping, $p_{w}(T)$ decreases at most linearly with the total pressure. Partly, this pressureinduced diminution in $p_{w}(T)$ is compensated for by evaporation of ice from the chamber walls because the wall temperature almost remains constant during pumping. As $p_{w, \text { ice }}(T)$ decreases exponentially with the gas temperature during expansion cooling, a rapid increase in $S_{\text {ice }}$ can be induced with a typical humidification rate $d S_{\text {ice }} / d t$ of about $0.2 / \mathrm{min}$ for a pumping speed of $120 \mathrm{~m}^{3} / \mathrm{h}$. With the maximum pumping speed of $200 \mathrm{~m}^{3} / \mathrm{h}$, the AIDA gas temperature can be reduced by as much as $10^{\circ} \mathrm{C}$ during pumping. For any initial temperature, this decrease is sufficient to reach or even go beyond saturation with respect to supercooled water during the expansion. The expansion cooling cycles thereby allow for investigating the heterogeneous ice nucleation potential of solid ice nuclei in both the condensation and deposition mode.

Accurate time profiles of the water vapour pressure $p_{w}(T)$ during the expansion cooling cycles are deduced from direct tuneable diode laser (TDL) absorption measurements. The employed room-temperature, near-infrared $(1370 \pm 2 \mathrm{~nm})$ telecommunication-type diode laser is coupled via an optical fibre into an open-path White-type multiple reflection cell whose mirrors are directly mounted onto the interior walls of the AIDA chamber. The optical path length of the White cell is currently adjusted between 23 and $84 \mathrm{~m}$, depending on the water vapour concentration. By modulation of the diode laser current, the entire absorption line profile of a selected rovibrational water vapour transition is scanned, integrated, and converted to water vapour mixing ratios at a temporal resolution of about $1 \mathrm{~s}$. As a major benefit, the 
interstitial water vapour concentration can be inferred even in the presence of dense clouds of supercooled water and/or ice particles. By dividing the recorded $p_{w}(T)$ time profiles through the saturation water vapour pressures over ice and liquid water, calculated with the equations from Murphy and Koop (2005) for the measured spatial means of the AIDA gas temperature, the time evolutions of the saturation ratios with respect to ice $\left(S_{\text {ice }}\right)$ and supercooled water $\left(S_{\text {liq }}\right)$ are obtained. The absolute accuracy of the TDL measurements is dominated by the line strength uncertainty of $\pm 3 \%$ (Wagner et al., 2008). Supplementing the TDL humidity measurements, the total water mixing ratio, i.e., the sum of interstitial water vapour and evaporated condensed water from the aerosol and/or cloud particles, is measured with a fast highprecision chilled mirror hygrometer (MBW, model 373) at a time resolution of $1 \mathrm{~s}$. The hygrometer is arranged outside the thermostated housing of the AIDA chamber and samples pass through a stainless steel tube that is heated to $303 \mathrm{~K}$.

Three important optical instruments are used for obtaining information about the number concentration, size, shape, and chemical composition of the investigated aerosol and cloud particles. A set of two optical particle counters (OPC1 and OPC2, type WELAS2000, Palas) is mounted to the bottom of the AIDA chamber within its thermostated housing, employing strictly vertical sampling tubes to minimise sampling losses. Particle number concentrations and size distributions are inferred from measuring the pulses of white light scattered by single particles into an angle of $90 \pm 12^{\circ}$. Given the measurement ranges of these instruments $(0.7-$ $40 \mu \mathrm{m}, \mathrm{OPC} 1$; and $2.3-104 \mu \mathrm{m}, \mathrm{OPC} 2)$, only the tail of the aerosol size distribution towards large particle diameters will be covered. Cloud particles composed of micron-sized supercooled water droplets and/or ice crystals, however, are quantitatively counted and sized. Note that the size information for aspherical ice particles is somewhat ambiguous due to the dependence of the phase function on the particle shape and orientation in the detection volume. As a second tool, infrared extinction spectra of the aerosol and cloud particles are recorded in situ by coupling a FTIR spectrometer to a second open-path White-type multiple reflection cell with an optical path length that is adjustable between 23 and 257 $\mathrm{m}$. The infrared spectra are typically recorded from 6000 to $800 \mathrm{~cm}^{-1}$ at $4 \mathrm{~cm}^{-1}$ resolution. Infrared extinction is the sum of light absorption in the particles and light scattering by the particles. The absorption contribution typically reflects distinctive bands of organic and inorganic functional groups, and, concerning the present study, allows for discriminating aqueous oxalic acid solution droplets from solid anhydrous oxalic acid or oxalic acid dihydrate crystals (Braban et al., 2003) as well as for distinguishing supercooled water droplets from ice crystals (Zasetsky et al., 2005). The scattering contribution is sensitive to the particle size and in principle allows for a retrieval of the particle size distribution. For certain chemical species, depending on the particle size and the complex refractive index, also information about the particle shape is inherent in the spectral habitus of the infrared extinction bands. Measurements of laser light scattering and depolarisation are a further powerful tool to detect deliquescence and efflorescence phase transitions in sub-micron sized aerosol particles as well as to monitor the freezing of large supercooled water droplets to aspherical ice crystals. For this purpose, the laser beam of a continuous wave semiconductor laser (Coherent, $\lambda=488 \mathrm{~nm}$ ) is directed horizontally through the AIDA chamber. The scattered light intensities are measured in the forward ( $I_{\text {for }}$, scattering angle $2^{\circ}$ ) and polarisation resolved in the backward direction ( $I_{\text {back,par }}, I_{\text {back,per }}$, scattering angle $178^{\circ}$ ), with $I_{\text {back,par }}$ and $I_{\text {back,per }}$ denoting the backscattered intensities parallel and perpendicular to the incident polarisation state of the light beam. The backscattering linear depolarisation ratio $\delta$ is then given by $\delta=I_{\text {back,per }} / I_{\text {back,par. }} \delta$ is zero for light scattering by spherical particles and in general clearly different from zero for light scattering by aspherical particles, thereby featuring a strong dependency on the particle size and shape (Mishchenko et al., 1996). Notable exceptions are aspherical particles with small size parameters and/or extreme aspect ratios. These particle types may reveal only a very weak backscattering linear depolarisation ratio (Zakharova and Mishchenko, 2000).

Concluding this section, we will give a tabular summary of the crystallisation and ice nucleation experiments (Table 1), serving as a look-up table for the detailed discussion in the following section. The first four columns denote the experiment number, the investigated chemical species (either oxalic acid or sodium oxalate), the initial AIDA gas temperature when adding the aerosol particles to the chamber, and the method for aerosol generation. The final column then briefly outlines the experimental procedure, including overall adjustments to the AIDA temperature and the number of expansion cooling cycles that have been performed at various temperatures.

\section{Results and discussion}

Given the broad diversity of the experimental procedures and the variety of the ice nucleation ability of the particles that is disclosed by the individual expansion runs, we describe and analyse the experiments step by step as they are listed in Table 1 , thereby gradually unravelling the intricate ice nucleation behaviour of the investigated species. As a guide for the reader, the discussion is subdivided into three sections; Sect. 3.1 addresses experiments 1, 2, and 3 where the ice nucleation ability of oxalic acid dihydrate particles that have crystallised or nucleated in AIDA at $T \leq 244 \mathrm{~K}$ is described, Sect. 3.2 compares the findings from Sect. 3.1 with the ice nucleation properties of anhydrous sodium oxalate particles generated at $244 \mathrm{~K}$, and Sect. 3.3 again focuses on the ice nucleability of oxalic acid dihydrate particles, this time generated by crystallisation in AIDA at $T>244 \mathrm{~K}$. 
Table 1. Compilation of the experimental procedures for the various crystallisation and ice nucleation experiments with oxalic acid and sodium oxalate. $T_{\text {inj }}$ denotes the initial AIDA gas temperature when adding the aerosol particles to the chamber. The procedure of each experiment is discussed in detail in Sect. 3. SMPS and APS number size distributions of the aerosol particles generated in Exp. 1, 2, 3, 4, and 6 are shown in panels a, c, e, b, and d of Fig. 3, respectively.

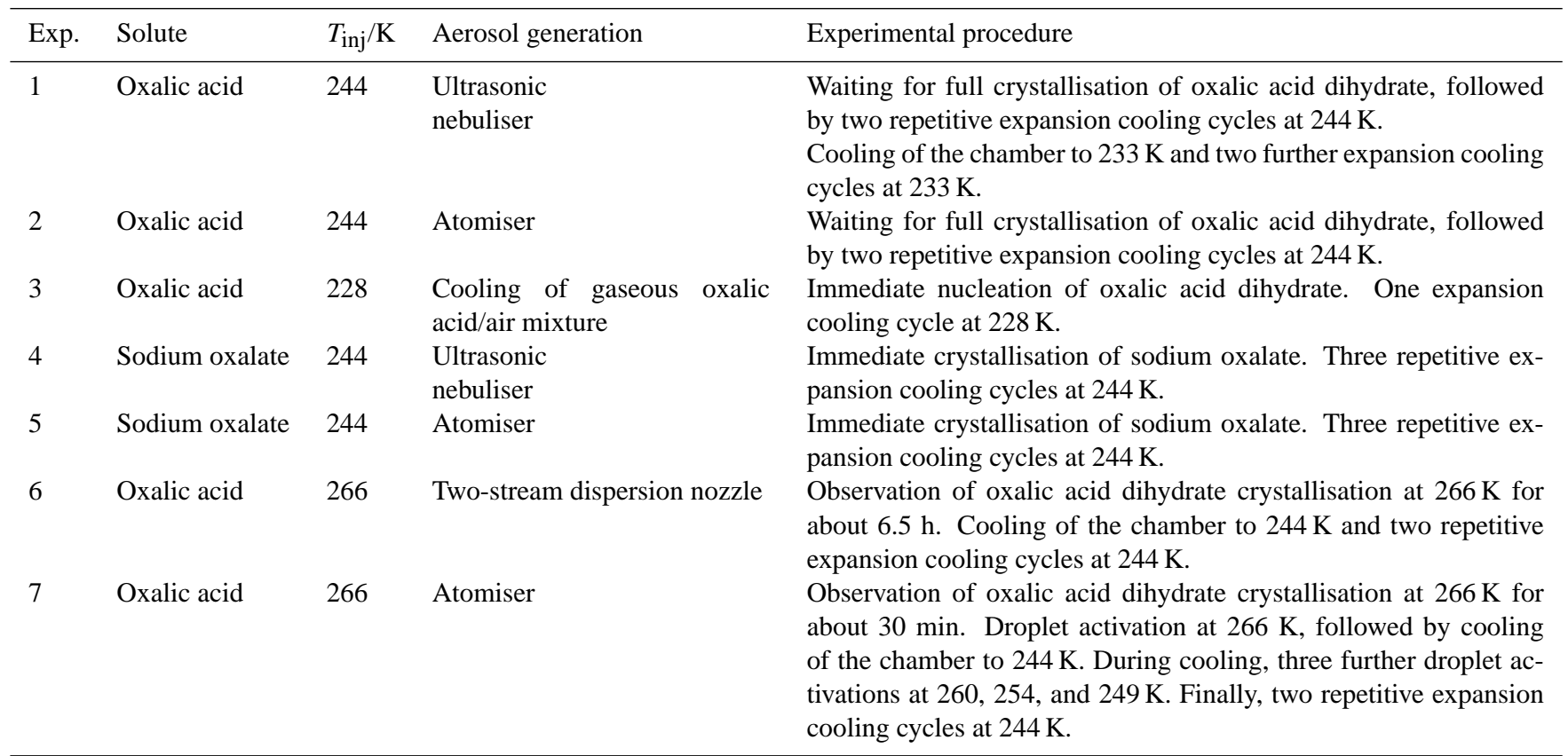

\subsection{Ice nucleation ability of oxalic acid dihydrate, crystallisation/nucleation at $T \leq \mathbf{2 4 4} \mathrm{K}$}

In the first type of experiment, oxalic acid solution droplets were added to the cooled AIDA chamber at $244 \mathrm{~K}$, either using an ultrasonic nebuliser (Exp. 1) or an atomiser (Exp. 2). As outlined in the introduction, the original purpose of these experiments was to generate supercooled, highly supersaturated aqueous oxalic acid solution droplets and mimic the trajectory A depicted in Fig. 1. Already in the course of the aerosol injection period, however, a continuous increase in the backscattering linear depolarisation ratio $\delta$ was observed (top panel of Fig. 4), indicating that the supersaturated oxalic acid solution droplets had started to crystallise. Note that the aerosol particles were added through a stainless-steel injection tube located at level one of the AIDA chamber, i.e., at the same height of the in situ light scattering and depolarisation measurements (Fig. 2). This causes the small-scale fluctuations of $\delta$ during the injection period $t_{\text {inj. }}$. After the stop of aerosol injection, the mixing fan, located at the bottom of the AIDA chamber and continuously operating since the start of aerosol addition, rapidly ensures homogeneous aerosol distribution throughout the chamber which leads to smoother traces of the depolarisation ratio. Constant values of $\delta=0.38$ and $\delta=0.18$ are reached about $2000 \mathrm{~s}$ and $4000 \mathrm{~s}$ after stopping the aerosol injection for experiments
1 and 2, respectively, pointing to the complete crystallisation of the aerosol population. Although the magnitude of $\delta$ is both size- and shape-dependent, these differences in $\delta$ are likely related to the clearly different particle sizes obtained by either ultrasonic nebulisation or atomisation, see panels a (Exp. 1) and c (Exp. 2) of Fig. 3. Simultaneously recorded infrared extinction spectra provide evidence for the chemical nature of the crystallised particulates. Four spectra recordings, monitored at different times during the injection and crystallisation period of Exp. 2, are shown in the bottom panel of Fig. 4. Spectrum (a) features a still comparatively broad extinction band in the $\mathrm{O}-\mathrm{H}$ stretching regime between 3700 and $3000 \mathrm{~cm}^{-1}$ caused by the presence of still unfrozen aqueous oxalic acid solution droplets, but at the same time already bares a clear spectral imprint of crystallised oxalic acid dihydrate particles, namely the doublet signature at about 3480 and $3415 \mathrm{~cm}^{-1}$ due to the hydration water. The doublet structure of the C-O stretching mode at $1250 \mathrm{~cm}^{-1}$ is a further indication for the presence of a mixture of supercooled aqueous oxalic acid solution droplets and oxalic acid dihydrate crystals, its low-wavenumber component at $1240 \mathrm{~cm}^{-1}$ attributable to concentrated aqueous solutions droplets and its high-wavenumber component at $1270 \mathrm{~cm}^{-1}$ attributable to oxalic acid dihydrate. At later times during the injection (spectrum c) the relative contributions of the spectral features related to oxalic acid dihydrate gain in intensity. Spectrum 

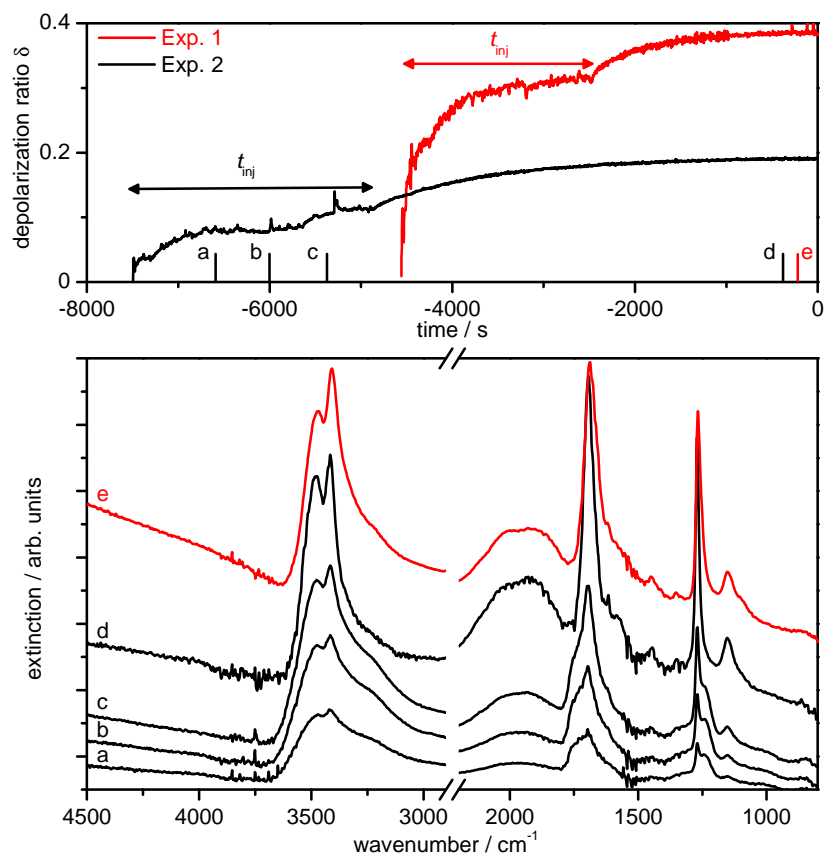

Fig. 4. Top panel: Temporal evolution of the backscattering linear depolarisation ratio $\delta$ after starting the addition of aqueous oxalic acid solution droplets to the AIDA chamber at $244 \mathrm{~K}$ with an ultrasonic nebuliser (Exp. 1) and an atomiser (Exp. 2). The horizontal arrows denote the overall time period of aerosol injection $\left(t_{\text {inj }}\right)$. Time zero denotes the start of the first expansion cooling experiment that was performed later on to investigate the ice nucleation potential of the added aerosol particles. Bottom panel: Infrared extinction spectra recorded at different time steps during the injection and crystallisation periods of Exp. 1 and Exp. 2, as indicated by the small vertical bars on the time scale in the top panel.

(d) finally represents a completely crystallised aerosol population and closely matches the infrared spectrum of oxalic acid dihydrate measured by Braban et al. (2003). For Exp. 1 , only the final infrared spectrum after full crystallisation is depicted (trace e). Again, oxalic acid dihydrate can be identified as the crystallisation product. The larger particle size in comparison with Exp. 2 leads to an increased contribution of light scattering to overall extinction, manifesting itself in a slight dispersion feature that is superimposed on the $3500 \mathrm{~cm}^{-1}$ doublet signature.

As apparent from Fig. 1 and already indicated in the introductory section, the composition of the injected oxalic acid solution droplets, initially prepared from dilute solutions of 4-8 wt $\%$ oxalic acid, will concentrate to about $62 \mathrm{wt} \%$ oxalic acid when exposed to ice saturated conditions at $244 \mathrm{~K}$. Given that the ambient relative humidity inside the AIDA chamber is typically $5-10 \%$ lower than ice saturation due to the internal heat spots, an even higher solute concentration of about $67 \mathrm{wt} \%$ would be obtained. To our knowledge, there is no previous literature report on the possibility to maintain such highly supersaturated oxalic acid solution droplets as used in the present study in a supercooled liquid state at low temperatures over a long period of time. The maximum oxalic acid concentration in the emulsified solutions investigated by Zobrist et al. (2006) amounted to $19.87 \mathrm{wt} \%$. In the first cooling cycle, this solution could be cooled to the homogeneous freezing temperature of $222.9 \mathrm{~K}$ without showing crystallisation. At room temperature, oxalic acid solution droplets levitated in an electrodynamic balance could be concentrated up to about $80 \mathrm{wt} \%$ before efflorescing at a relative humidity of $52-57 \%$ (Peng et al., 2001). As a comparison, the initial relative humidity with respect to supercooled water in experiments 1 and 2 amounted to about $70 \%$. In contradiction to the Peng et al. (2001) result, numerous studies have addressed the difficulty to prepare an aerosol population of crystalline oxalic acid particles by spray-drying of aqueous solutions at room-temperature even at a very low relative humidity of 5\% (Braban et al., 2003; Mikhailov et al., 2009; Prenni et al., 2001).

Without doubt, experiments conducted in a large-scale aerosol chamber such as AIDA are more susceptive to potential interferences caused by heterogeneous effects compared to experiments with levitated droplets or emulsified solutions. One could think of a number of sites in the chamber interior including e.g. the surfaces of the mirrors for the internal multiple reflection cells or the rotors of the mixing fan which could potentially induce the heterogeneous crystallisation of the supersaturated oxalic acid solution droplets. The pronounced, immediate increase in the depolarisation ratio directly after the start of aerosol addition as well as the fast crystallisation of the entire aerosol population in the $84 \mathrm{~m}^{3}$ sized vessel, however, can hardly be explained by heterogeneous crystallisation on a few selected sites. Moreover, as recently shown by experiments on the glass transition and the ice nucleating abilities of citric acid aerosols (Murray et al., 2010), it is indeed possible to maintain a population of supersaturated aqueous organic solution droplets at very low temperatures $(215 \mathrm{~K})$ in AIDA without any indication of heterogeneous crystallisation. With our present instrumentation, a further quantitative analysis of the crystallisation process in terms of deriving a crystallisation rate, i.e., the number of crystallisation events per unit volume of aqueous oxalic acid solution droplets per unit time, is not possible. For an analysis based on homogeneous nucleation theory, the time evolution of both the volume concentration of liquid droplets (not including crystallised droplets) and the number concentrations of crystallised and still unfrozen oxalic acid solution droplets have to be determined. The first quantity could in principle be derived from the FTIR extinction spectra but would necessitate accurate composition- and temperature-dependent infrared optical constants for both aqueous oxalic acid solution droplets and oxalic acid dihydrate which are currently not available. Moreover, separate and quantitative counting of the submicron-sized frozen and unfrozen solution droplets is extremely difficult to achieve. A promising instrument development in this context is the 

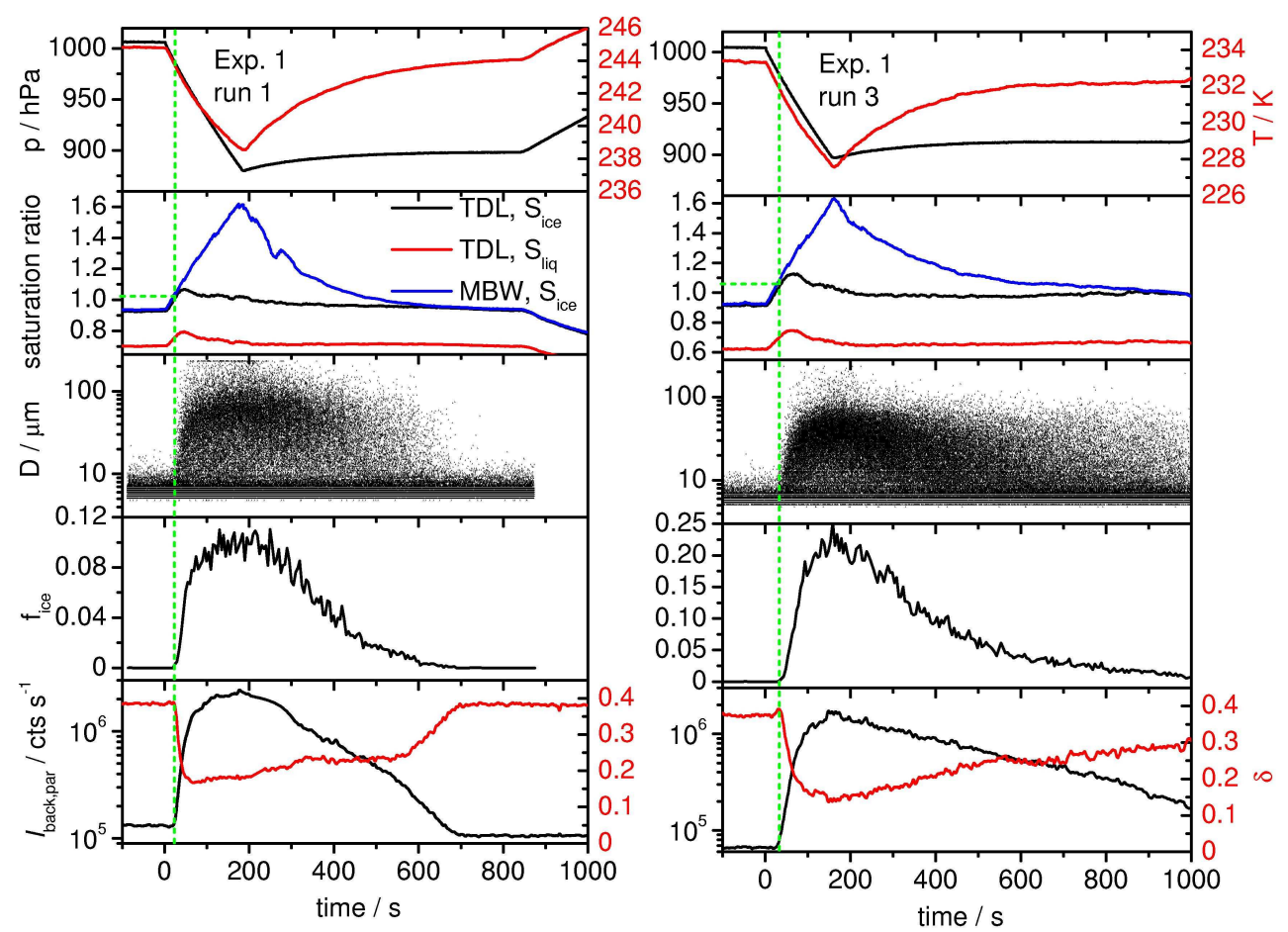

Fig. 5. Time series of various AIDA records during two expansion cooling cycles from Exp. 1. In each graph, time zero denotes the start of pumping. For run 1, time zero corresponds to $t=0$ on the time scale in the top panel of Fig. 4 . The five panels contain the following data. Panel 1: AIDA pressure (black line) and mean gas temperature (red line). Panel 2: Saturation ratios with respect to ice ( $S_{\text {ice, }}$, black and blue line) and supercooled water ( $S_{\text {liq }}$, red line). $S_{\text {liq }}$ is only shown for the gas-phase water concentration measured by TDL absorption whereas $S_{\text {ice }}$ is plotted for both the gas-phase and total water concentration as measured ex situ with the MBW chilled mirror hygrometer. Panel 3: Size of individual particles detected by the OPC2. Panel 4: Number fraction of ice-active aerosol particles. Panel 5: Backscattering intensity parallel to the incident polarisation state of the laser light (black line) and backscattering linear depolarisation ratio $\delta$ (red line). See text for details.

Small Ice Detector probe SID3 constructed at the University of Hertfordshire (http://strc.herts.ac.uk/pi/proj.html). The instrument measures the spatial scattering patterns from individual particles down to sizes of about $1 \mu \mathrm{m}$ and, as inherent in its name, was primarily constructed to reveal the crystal morphology of ice crystals down to sizes too small to be resolved by conventional imaging instruments. Because a part of the aerosol size distribution in Exp. 1 extended into the $>1$ micron size range, SID3 was tested for the first time at AIDA as a tool for the shape analysis of large aerosol particles. More theoretical work, however, is needed to confirm that the recorded spatial scattering patterns indeed allow for a unique discrimination between spherical solution droplets and aspherical frozen droplets even for sizes down to $1 \mu \mathrm{m}$ or, alternatively, to determine the threshold size above which such distinction is possible. In a future crystallisation experiment, an aerosol would then have to be generated whose entire number size distribution falls into a size regime that can be quantitatively counted and shape-classified by SID3.

We will now focus our discussion on the ice nucleation potential of the crystallised oxalic acid dihydrate particles generated during experiments 1 and 2. Time series of various
AIDA data recorded during two different expansion cooling cycles from Exp. 1 are plotted in Fig. 5. The contents of each graph in Fig. 5 are arranged as follows. The top row panel shows the time series of the AIDA pressure (black line) and the mean AIDA gas temperature (red line) in the course of the expansion experiment. In the second row, the time evolution of the saturation ratios with respect to ice $\left(S_{\text {ice }}\right.$, black line) and supercooled water ( $S_{\text {liq }}$, red line) from the TDL absorption measurements are plotted. In addition, the trace of $S_{\text {ice }}$ obtained for the total water concentration measured by the MBW frost point hygrometer is shown as blue line. For the aerosol mass concentrations employed in the current experiments, any aerosol water content, if present, is usually negligible compared to the interstitial water vapour concentration. The traces of $S_{\text {ice }}$ from the TDL and MBW measurements therefore coincide as long as no clouds of supercooled water and/or ice are formed. Scatter plots from the optical particle counter OPC2 are shown in the third row. Each dot represents a single particle count event in one of the OPC2 size channels. It is usually feasible to introduce an optical threshold size to distinguish between comparatively small interstitial aerosol particles and large ice crystals that 
have nucleated during an expansion cooling cycle. Counting all particles above the threshold size then yields the ice particle number concentration $N_{\text {ice }}$. By dividing $N_{\text {ice }}$ through the prevailing aerosol number concentration, the so-called iceactive fraction $f_{\text {ice }}$ of an aerosol population is obtained. The time evolution of this quantity is shown in the fourth panel of each graph. The final panel contains records from the in situ laser light scattering and depolarisation measurements, namely time series of the backscattered intensity $I_{\text {back,par }}$ parallel to the incident polarisation state of the laser (black line) and the linear backscattering depolarisation ratio $\delta$ (red line).

The left panel of Fig. 5 shows AIDA data from the first expansion run conducted in the course of Exp. 1. Pumping was started at time zero (see Fig. 4) after the complete crystallisation of the injected oxalic acid solution droplets to oxalic acid dihydrate at initial saturation ratios of $S_{\text {ice }}=0.93$ and $S_{\text {liq }}=0.70$. The oxalic acid dihydrate crystals are optically counted by the OPC 2 up to a threshold size of about $10 \mu \mathrm{m}$, which, as mentioned above, can only be interpreted as an apparent particle diameter due to the ambiguous sizing of aspherical particles. Shortly after the start of pumping, when reaching a threshold ice saturation ratio $S_{\text {ice }}$ of about 1.03 (as indicated by the dashed green lines), a dense cloud of large ice crystals is formed. The threshold is given as the prevailing relative humidity when the total ice particle number concentration, as measured by the OPC2, has exceeded a value of $1 \mathrm{~cm}^{-3}$. This definition is chosen, in favour of denoting the threshold relative humidity for ice nucleation on a certain percentage of the aerosol population, to directly compare our results with those from Kanji et al. (2008), see below. A different threshold definition would not change the major conclusions from our experiments. Albeit continuing with pumping after exceeding the threshold relative humidity, the nucleated ice crystals rapidly deplete the excess of water vapour in the gas phase. Therefore, $S_{\text {ice }}$ only gets to a peak value, $S_{\text {ice, max }}$, of about 1.07 during pumping before levelling of to $S_{\text {ice }}=1$. This value is preserved as long as a stable ice cloud is maintained in AIDA, i.e., before all ice crystals have either evaporated or grown large enough to fall to the bottom of the cloud chamber and be lost. The nucleation of large ice crystals is also documented by the sharp increase in the intensity of the backscattered laser light by more than one order of magnitude. In contrast, the intricate, non-linear dependency of $\delta$ on particle size and shape provokes that the depolarisation ratio of the large ice crystals is smaller than that of the oxalic acid dihydrate crystals. The data from Fig. 5 reveal that the crystallised oxalic acid dihydrate particles act as very efficient deposition mode ice nuclei. As apparent from the fourth panel, a significant number fraction with $f_{\text {ice }}=0.1$ has acted as a heterogeneous ice nucleus. The rapid depletion of the supersaturation may have prevented additional oxalic acid dihydrate crystals with a slightly higher activation threshold to become activated.

Three further expansion cooling cycles were performed with the aerosol loading from Exp. 1. Shortly after the ice cloud generated during run 1 had evaporated (at $t=800 \mathrm{~s}$, see Fig. 5), the chamber was refilled with dry, synthetic air to ambient pressure, leading to a temporary decrease in the ice saturation ratio. After reaching ambient pressure, it took about $30 \mathrm{~min}$ before the gas temperature and $S_{\text {ice }}$ regained their original values of $244 \mathrm{~K}$ and 0.93 , respectively. Then, another expansion run with the same time profiles of pressure and temperature was performed. The AIDA records from run 2 closely match those from run 1 and are therefore not explicitly shown. During the second expansion cycle, the critical ice saturation ratio at the onset of ice formation, $S_{\text {ice,crit }}$, amounted to about 1.05 . For $S_{\text {ice, max }}$ and $f_{\text {ice, }}$, values of 1.11 and 0.12 were observed. The slightly higher activation threshold during run 2 might be due to the fact that the most efficient ice nuclei from run 1 were no longer present. Early activation will go along with growth to the largest ice crystals that will preferentially be removed by sedimentation. On the other hand, the increase in $f_{\text {ice }}$ might be related to the slightly higher peak value for $S_{\text {ice }}$ that was attained during run 2 compared to run 1 . So, a part of less active ice nuclei that had no chance to become activated in run 1 can contribute to $f_{\text {ice }}$ in run 2 . Note that the slight variation in $S_{\text {ice,crit }}$ between run 1 and run 2 is less than the absolute accuracy of the TDL measurements which, as stated above, is mainly due to the line strength uncertainty. In the two repetitive expansion runs as well as in all subsequently described expansion cooling cycles that were started at $T \leq 244 \mathrm{~K}$, however, the same water vapour absorption line was scanned. Small relative variations in the critical ice saturation ratios might therefore indeed point to a modified ice nucleation ability of the investigated particles. After run 2, the AIDA chamber was refilled to ambient pressure and cooled to $233 \mathrm{~K}$ to probe the ice activity of the oxalic acid dihydrate crystals at a different temperature. The AIDA records from run 3 are shown in the right panel of Fig. 5. When starting the expansion at $233 \mathrm{~K}$, the ice cloud is formed at $S_{\text {ice, crit }}=1.06$ with attaining a maximum value of $S_{\text {ice, } \max }=1.13$ in the course of the expansion. As a notable difference to run 1 and run 2, a much higher ice-active fraction of $f_{\text {ice }}=0.22$ is observed. The results from run 3 could be closely reproduced in a succeeding expansion cycle after refilling the AIDA chamber to ambient pressure (run 4: $S_{\text {ice, } \text {,rit }}=1.08, S_{\text {ice, } \max }=1.16, f_{\text {ice }}=0.22$ ). Such increase in $f_{\text {ice }}$ with decreasing temperature has been frequently observed in heterogeneous ice nucleation studies (Pruppacher and Klett, 1997), as e.g. for deposition mode ice nucleation on a variety of mineral particulates (Roberts and Hallett, 1968).

The oxalic acid dihydrate particles from Exp. 2 (aerosol generation with the atomiser) were probed on their ice nucleating ability in two successive expansion cooling cycles started at $T=244 \mathrm{~K}$. Also a fraction of up to $0.5 \%$ of these smaller crystals proved to be efficient deposition mode ice nuclei, as evidenced by very low critical ice saturation ratios of 1.06 and 1.08 in the two succeeding expansion runs. Note that the ice nucleation behaviour observed in Exp. 1 


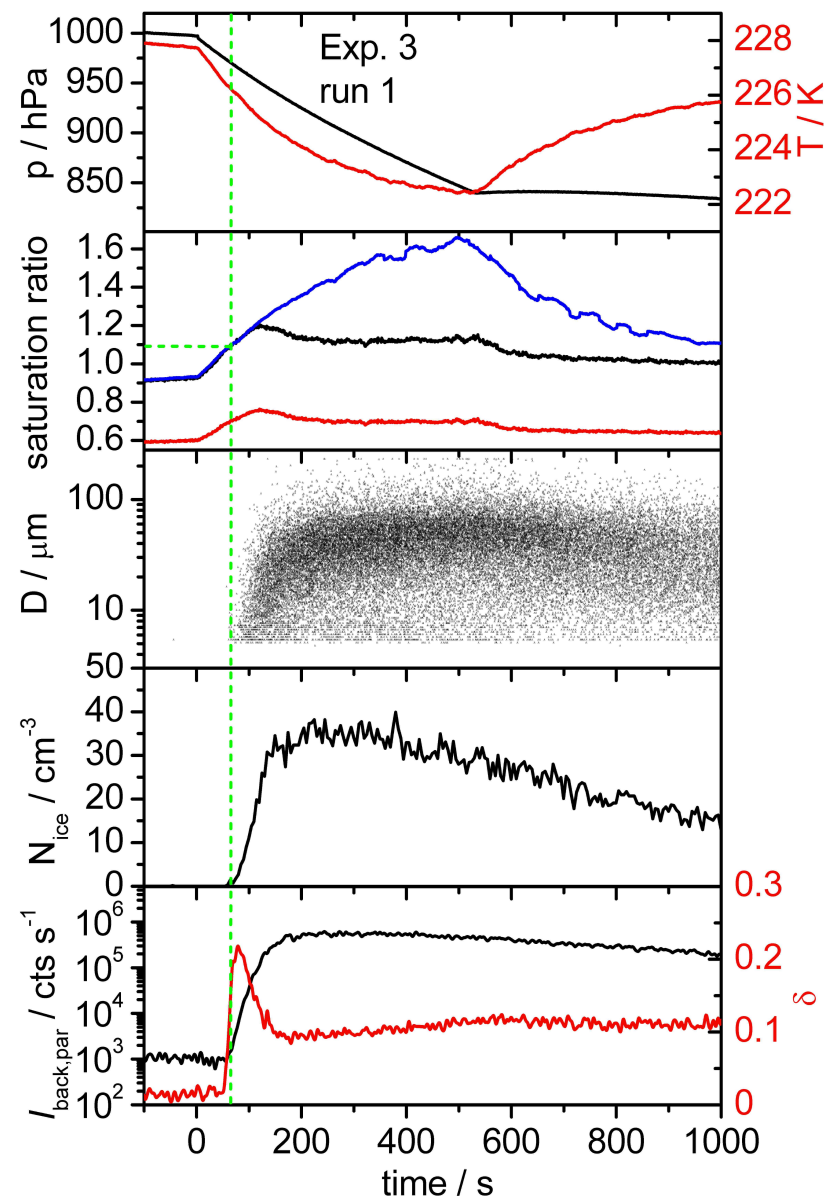

Fig. 6. Time series of various AIDA records during the first expansion cooling cycle from Exp. 3. The individual panels contain the same measurements as in Fig. 5, except from panel 4 where the ice particle number concentration $N_{\text {ice }}$ instead of the ice-active fraction $f_{\text {ice }}$ is shown.

and Exp. 2 was highly reproducible. Both types of experiments were repeated at least two times, yielding very similar values for $S_{\text {ice,crit }}$ and $f_{\text {ice. }}$. Figure 6 shows the results from an expansion cooling cycle with the smallest, nanometresized oxalic acid dihydrate crystallites generated by adding the gaseous oxalic acid/air mixture into the AIDA chamber at $228 \mathrm{~K}$ (Exp. 3 in Table 1, see also panel e in Fig. 3). The blue trace in the top panel of Fig. 7 shows the infrared spectrum of the nucleated particulates after an injection time of $2 \mathrm{~h}$. Albeit being noisier due to the lower aerosol mass concentration, the extinction spectrum clearly bares the signatures of oxalic acid dihydrate. In contrast to the particles generated during Exp. 1 and Exp. 2, these tiny crystallites do not provoke any notable depolarisation of the backscattered laser light and do not extend into the measurement range of the OPC2. During the expansion, a dense ice cloud is formed at $S_{\text {ice, crit }}=1.09$. The linear depolarisation ratio shows a narrow peak in the first period of the nucleation event, i.e., dur-
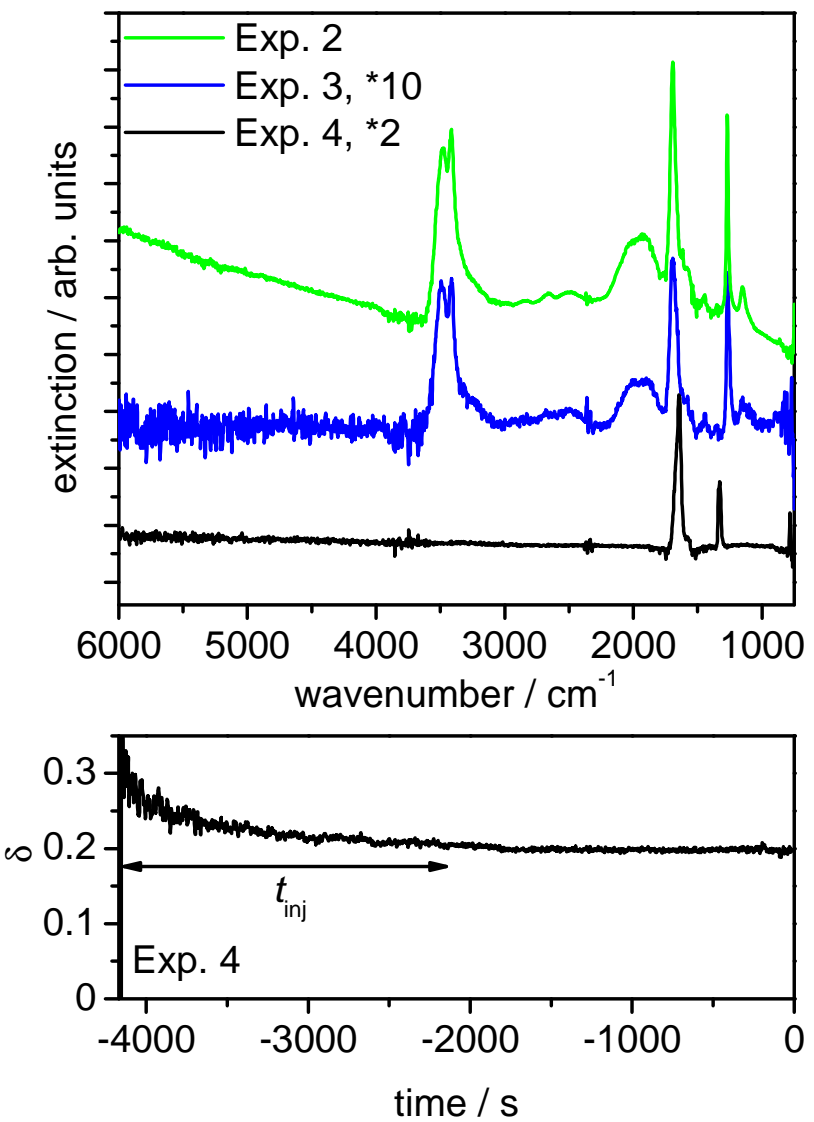

Fig. 7. Top panel: Infrared extinction spectra of oxalic acid dihydrate particles generated during Exp. 2 (green line, corresponding to spectrum d shown in Fig. 4) and Exp. 3 (blue line, scaled by a factor of 10). The black trace shows the spectral signature of sodium oxalate particles recorded at $t=-1600 \mathrm{~s}$ during Exp. 4 (see timescale in the bottom panel). Bottom panel: Temporal evolution of the backscattering linear depolarisation ratio $\delta$ after starting the addition of aqueous sodium oxalate solution droplets to the AIDA chamber at $244 \mathrm{~K}$ with an ultrasonic nebuliser (Exp. 4).

ing the time of strong ice particle growth. This feature can be accurately modelled by T-matrix calculations and again reflects the pronounced size-dependency of $\delta$ (Wagner et al., 2009). A maximum ice particle number concentration of about $40 \mathrm{~cm}^{-3}$ is formed during the expansion which is comparable to the $N_{\text {ice }}$ values obtained in runs $1-4$ of Exp. 1 . As the aerosol number concentration of the oxalic acid dihydrate crystallites, however, amounts to about $40000 \mathrm{~cm}^{-3}$, only a comparatively small $0.1 \%$ fraction of the overall aerosol population has acted as a heterogeneous ice nucleus.

The observed high ice nucleation ability of solid oxalic acid dihydrate particles in the deposition mode is consistent with the findings from Kanji et al. (2008). An estimate of the aerosol surface concentrations from the measured SMPS/APS size distributions assuming spherical particles yields values of about $1.2 \times 10^{-5}, 0.78 \times 10^{-5}$, and 
$0.13 \times 10^{-5} \mathrm{~cm}^{2}$ per $\mathrm{cm}^{3}$ volume of AIDA prior to the first expansion runs in Exp. 1, 2, and 3, respectively. The corresponding critical ice saturation ratios $S_{\text {ice,crit }}$ of 1.03, 1.06, and 1.09 that were observed in the course of these expansion runs can therefore be interpreted as the threshold relative humidities to nucleate one ice particle on aerosol surface areas of $1.2 \cdot 10^{-5}, 0.78 \cdot 10^{-5}$, and $0.13 \times 10^{-5} \mathrm{~cm}^{2}$. Thus, even somewhat lower threshold saturation ratios for deposition mode ice nucleation were observed in our study although the particulate surface areas were smaller than those in the Kanji et al. (2008) experiments. In contradiction to our results, Prenni et al. (2001) have noted that oxalic acid is not effective in nucleating ice until reaching water saturation at $T<228 \mathrm{~K}$. But as summarised in the introduction, the phase of the investigated particles remains uncertain. Given that the particles whose ice nucleation ability was tested in the CFDC chamber revealed a continuous water uptake at a relative humidity between 45 and $91 \%$, it is unlikely that they were crystalline oxalic acid dihydrate particles but rather concentrated solution droplets or, in accordance with the hypothesis from Mikhailov et al. (2009), gel-like amorphous particles. In addition, the authors present critical ice saturation ratios when $1 \%$ of the 50 and $100 \mathrm{~nm}$ particles have formed ice. It is not specified whether a smaller fraction of the oxalic acid particles potentially has formed ice at lower supersaturations, provided that this would be detectable with the experimental setup. Assuming that the oxalic acid particles probed by Prenni et al. (2001) were indeed amorphous, we emphasise that their comparatively low ice nucleability in relation to the oxalic acid dihydrate crystals from experiments $1-3$ should not be interpreted as a common attribute of the amorphous state. For example, a recent AIDA study has shown that amorphous citric acid aerosol particles in a glassy state heterogeneously nucleated ice below the freezing threshold for homogeneous nucleation in liquid droplets, partly revealing threshold $S_{\text {ice,crit }}$ values as low as 1.2 (Murray et al., 2010).

Parsons et al. (2004) have addressed the poor ice nucleation ability of malonic, succinic, glutaric, and adipic acid in the deposition mode at temperatures above $243 \mathrm{~K}$. It is therefore tempting to ascribe the prominent ice nucleation behaviour of oxalic acid dihydrate amongst all other investigated dicarboxylic acids to its intrinsic chemical structure. Note that also Zobrist et al. (2006) have highlighted the particular role of immersed oxalic acid (dihydrate) crystals as the only species capable of inducing heterogeneous ice nucleation. In particular the O-H-O hydrogen bonds by which the two molecules of water are interconnected in between the carboxyl groups in the structure of oxalic acid dihydrate might be, if present at the particle surface, suitable sites to explain the extraordinary good ice-nucleability of this compound (Pruppacher and Klett, 1997). Anticipating the results from further crystallisation experiments that were already briefly addressed in the introduction and that will be discussed in detail in Sect. 3.3, however, suggest that also the surface structure in terms of defects like cracks, steps, or dislocations might be an important factor. Oxalic acid dihydrate crystals that were generated in a different manner, i.e., by crystallisation from less supersaturated aqueous solution droplets at $T=266 \mathrm{~K}$ over a timescale of many hours, did not reveal such a high deposition mode ice activity when cooled to $244 \mathrm{~K}$ as those particles that have rapidly crystallised from highly supersaturated solution droplets directly at $244 \mathrm{~K}$. In order to give reason for their outstanding ice-nucleability, one might therefore also speculate that polycrystalline particles with numerous defects are formed when oxalic acid dihydrate particles rapidly crystallise from highly supersaturated solution droplets at low temperatures. Temperature and supersaturation are known to be key parameters that influence size and shape of crystals grown from aqueous solutions (Omar and Ulrich, 2006; Torgesen and Strassburger, 1964). This interpretation would be in agreement with the results from the study by Shilling et al. (2006) about heterogeneous ice nucleation on spray-deposited ammonium sulphate and maleic acid particles. As shown by scanning electron microscope images, the investigated particles contained a significant number of defects and appeared to be polycrystalline. This extensive surface structure might be the reason that the particles acted as efficient ice nuclei for heterogeneous deposition nucleation with $S_{\text {ice, crit }}$ as low as 1.05 at $T=240 \mathrm{~K}$. Also Parsons et al. (2004) considered that the investigated saturated dicarboxylic acids C3-C6 might be more important in ice cloud formation if the particles had more defects than those generated in their study. And indeed, deposition mode ice nucleation on solid glutaric acid particles (C5) with

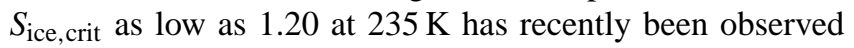
(Baustian et al., 2010). The active site explanation would also account for the observed dependence of $f_{\text {ice }}$ on the size of the oxalic acid dihydrate particles. Smaller aerosol particles will contain a lower number of defects or active sites that are capable of triggering ice nucleation. Summarising our results, $f_{\text {ice }}$ ranged from $0.10-0.22$ at $T=244-233 \mathrm{~K}$ for $d_{p}=0.8 \mu \mathrm{m}$ (Exp. 1), whereas maximum ice-active fractions of about 0.5 and $0.1 \%$ were encountered in Exp. 2 and Exp. 3 with the $0.1 \mu \mathrm{m}$ and $0.03 \mu \mathrm{m}$ sized particles at $T=244$ and $228 \mathrm{~K}$, respectively. Recently, Marcolli et al. (2007) have modelled freezing experiments on the heterogeneous ice nucleation ability of immersed Arizona test dust (ATD) particles with an occurrence probability function of active sites. Their analysis indicates that an ATD particle must have a diameter of at least $0.1 \mu \mathrm{m}$ to exhibit on average one active site. Based on the results from Exp. 3, the minimum threshold size for rapidly crystallised oxalic acid dihydrate particles is significantly smaller than that for ATD, further underlining their extraordinary high ice nucleability, as also evidenced by the low critical ice saturation ratio in comparison with heterogeneous ice nucleation by $50 \mathrm{~nm}$-sized dust particles (Archuleta et al., 2005). 

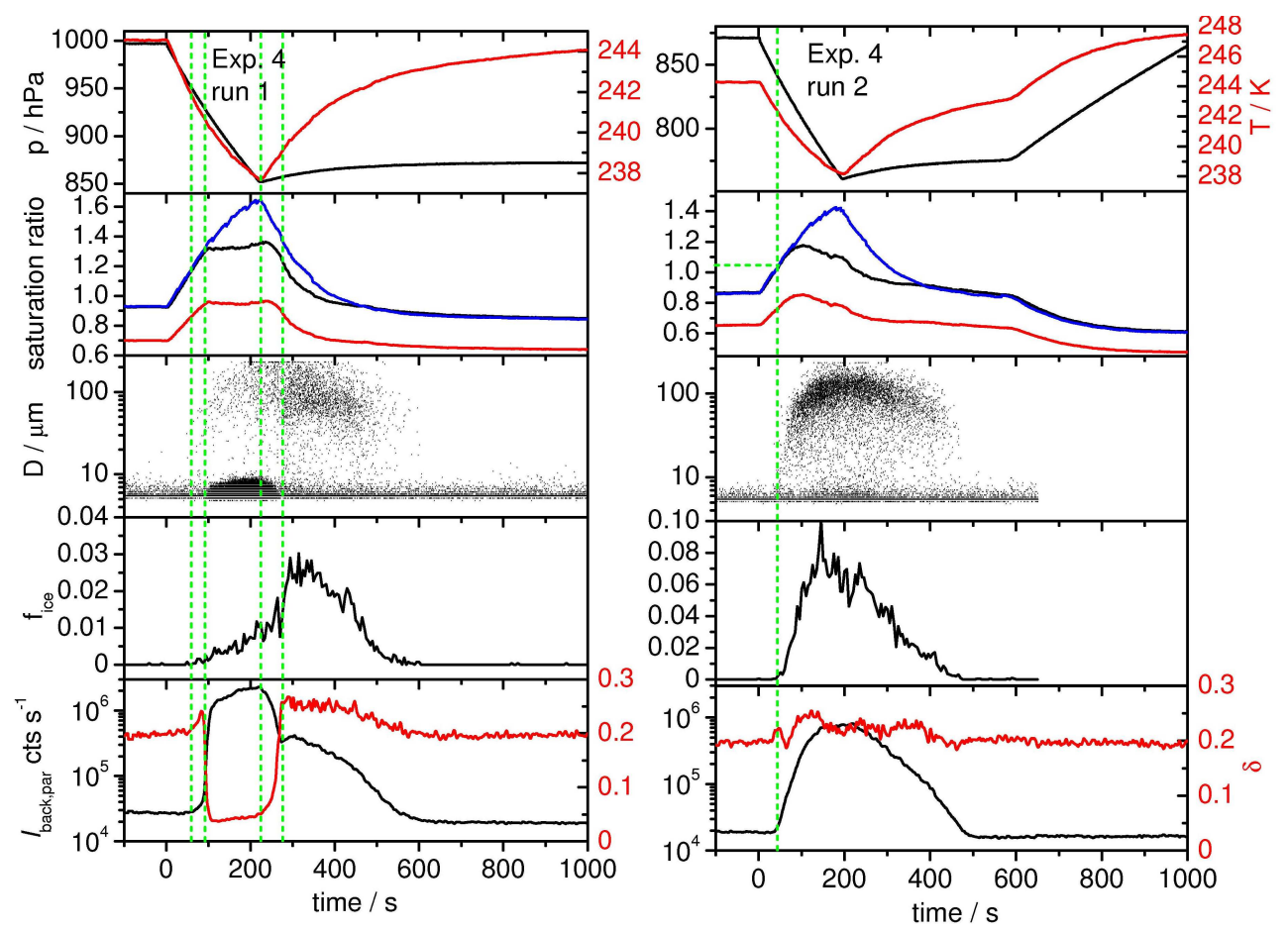

Fig. 8. Time series of various AIDA records during two expansion cooling cycles from Exp. 4. In each graph, time zero denotes the start of pumping. For run 1, time zero corresponds to $t=0$ on the time scale in the bottom panel of Fig. 7. The individual panels show the same measurements as in Fig. 5.

\subsection{Ice nucleation ability of sodium oxalate, crystallisation at $T=244 \mathrm{~K}$}

In order to compare the ice nucleability of oxalic acid dihydrate with a different chemical species, we have performed a similar set of experiments with sodium oxalate particles. Exp. 4 and Exp. 5 are duplicates of Exp. 1 and Exp. 2 where aqueous solutions of $3 \mathrm{wt} \%$ sodium oxalate were injected into the AIDA chamber at $244 \mathrm{~K}$ with an ultrasonic nebuliser (Exp. 4) and an atomiser (Exp. 5). In contrast to the injection periods with aqueous oxalic acid solutions, not a continuous but an immediate, step-wise increase in the depolarisation ratio $\delta$ after the start of aerosol addition was monitored (Fig. 7, lower panel, showing the trace of $\delta$ during Exp. 4). This indicates that the supersaturated solution droplets instantly crystallised in AIDA at $T=244 \mathrm{~K}$ and $S_{\text {liq }}=0.7$. The simultaneously recorded infrared extinction spectrum of the particulates (black trace in the top panel of Fig. 7) closely matches previously recorded spectra of sodium oxalate in alkali halide matrices (Hartman and Hisatsune, 1967), showing major bands at 1645,1330 , and $783 \mathrm{~cm}^{-1}$. The absence of any extinction band in the $\mathrm{O}-\mathrm{H}$ stretching regime reveals that anhydrous crystals of sodium oxalate have formed. Due to the lower employed solute concentration, caused by the lower solubility of sodium oxalate in water compared to oxalic acid, the median particle diameter of the crystallised particles in Exp. 4 was smaller than in Exp. 1 (see panels a and b in Fig. 3). The smaller particle size of the sodium oxalate crystals might be the primary reason for the overall lower value of $\delta$ in comparison with the oxalic acid dihydrate particles from Exp. 1. The observed immediate crystallisation of sodium oxalate is in agreement with previously recorded water cycles of sodium oxalate particles levitated in an electrodynamic balance at room temperature, showing an efflorescence transition at $\mathrm{RH}=72-75 \%$ (Peng and Chan, 2001).

The left panel of Fig. 8 shows the AIDA records from the first expansion run with the crystallised sodium oxalate particles. In remarkable contrast to all previously reported expansion cycles with oxalic acid dihydrate, the freshly crystallised sodium oxalate particles did not act as efficient ice nuclei in the deposition mode at low ice supersaturations. The slight increase in the backscattering linear depolarisation ratio that occurs at $t=50 \mathrm{~s}$ (first vertical green line in Fig. 8), accompanied by the detection of a very few number of larger ice crystals in the OPC2, is the only indication for ice activity in the deposition mode. The number of nucleated ice crystals is too small to provoke a diminution of the ice supersaturation. Instead, the relative humidity further increases until at $t=90 \mathrm{~s}$ saturation with respect to supercooled water is reached (second green line). At water saturation, a dense cloud of supercooled water droplets with $D<10 \mu \mathrm{m}$ is formed (see OPC2 scatter plot).Within the estimated measurement accuracy of $10 \%$, the number concentration of cloud droplets detected by 
the OPC2 and independently retrieved from the FTIR extinction spectra (Wagner et al., 2006) corresponds to the number concentration of the sodium oxalate particles measured by the CPC before the start of the expansion, indicating that almost all aerosol particles have become activated. The formation of spherical cloud droplets causes a sharp drop in the depolarisation ratio, levelling off at a value slightly above zero due to the presence of the small number of aspherical ice crystals. With droplet cloud formation, a clear and continuous increase in the ice particle number concentration was monitored (the ice particles appear at larger apparent diameters with $D>10 \mu \mathrm{m}$ in the OPC2 scatter plot), indicating that a fraction of the sodium oxalate particles that are not active in deposition mode ice nucleation is active in the condensation mode. This result underlines that the sodium oxalate crystals are not completely dissolved during $\mathrm{CCN}$ activation and subsequent droplet growth. At $t=210 \mathrm{~s}$ when pumping is stopped (third green line), $f_{\text {ice }}$ has reached a value of about $1 \%$. Recalling the results from the first expansion run with freshly crystallised oxalic acid dihydrate particles of a similar, only slightly larger size (Exp. 1), 10\% of the aerosol population had already been ice-active in the deposition mode at $S_{\text {ice }} \leq 1.07$. At first glance, this striking difference supports the theory that the specific chemical structure of oxalic acid dihydrate with its included hydration water accounts for the high ice nucleability of this particular compound. The ice nucleation activity of the sodium oxalate particles, however, was significantly enhanced in the later period of expansion run 1 and in two succeeding expansion cooling cycles.

After the stop of pumping at $t=210$ during run 1 , it took about one minute for the cloud of supercooled water droplets to evaporate. At $t=270 \mathrm{~s}$ (fourth green line), the depolarisation ratio has regained its original value before the droplet cloud has formed, indicating that again crystalline sodium oxalate particles are present. $I_{\text {back, par }}$ has decreased by an order of magnitude, reflecting the contribution of light scattering gone lost by the evaporation of the cloud droplets. The remaining signal in relation to the background level at time zero now contains only the scattering contribution from the nucleated ice crystals that are still present. Directly after the evaporation of the cloud droplets, $f_{\text {ice }}$ suddenly increases up to a value of about 0.03 . This second ice nucleation event can also be clearly seen in the OPC 2 scatter plot by the appearance of a new, denser point cloud after $t=270 \mathrm{~s}$. Note that the gas temperature has almost reached the homogeneous freezing temperature of pure water droplets during the first expansion run, i.e., when pumping was stopped at $t=210 \mathrm{~s}, T$ was only a few tenth of a Kelvin higher than the upper threshold of the temperature intervals for which homogeneous ice nucleation rates were determined in the former AIDA study by Benz et al. (2005). One might therefore be tempted to explain the second ice nucleation event by homogeneous freezing. In such a case, however, one would have to give explanation for the delayed detection of the nucleated ice crystals since the second ice crystal mode only appeared in the OPC2 scatter plot $60 \mathrm{~s}$ after pumping had been stopped when the gas temperature had already increased to $239 \mathrm{~K}$. Such delay of ice particle detection is a crucial issue when analysing ice nucleation experiments at very low temperatures because the growth time of ice crystals to detectable sizes has to be taken into account (Möhler et al., 2006). Respective growth times were estimated by Möhler et al. (2006) to $4 \mathrm{~s}$ at $223 \mathrm{~K}, 8 \mathrm{~s}$ at $210 \mathrm{~K}$, and $50 \mathrm{~s}$ at $196 \mathrm{~K}$. In contrast, if already micronsized supercooled water droplets would have frozen close to $t=210 \mathrm{~s}$ in the first expansion run of Exp. 4, the generated micron-sized ice crystals should have been immediately detected by the OPC 2 and not only after a delay of $60 \mathrm{~s}$. We therefore propose a different explanation for the second ice crystal mode. Note that after the evaporation of the cloud water at $t=270 \mathrm{~s}$, the bare sodium oxalate particles are exposed to an environment that is still supersaturated with respect to the ice phase ( $S_{\text {ice }}$ about 1.27 ) and can thus again act as deposition mode ice nuclei. Obviously, a significant fraction of the sodium oxalate crystals attains a much higher ice nucleation activity in the deposition mode when processed in the course of the droplet activation and evaporation cycle. One might discuss this behaviour in the context of the wellknown phenomenon of pre-activation of insoluble ice nuclei in heterogeneous ice nucleation (Pruppacher and Klett, 1997; Roberts and Hallett, 1968; Vali, 2008). In previous studies, various experimental conditions under which solid ice nuclei have become activated to display an improved ice nucleation potential are reported. For some substances, it was necessary to form ice crystals on them in a first nucleation event (Mossop, 1956). Small embryos of ice might then survive in suited cavities or crevices at the particle surface even at relative humidities substantially below $S_{\text {ice }}=1$ and cause a lower threshold relative humidity for ice formation in a succeeding nucleation experiment. As an alternative interpretation, the ice crystals may imprint their structure on the surface of soft materials, yielding a surface structure that more closely resembles the ice lattice and that can then act as an activated site to promote ice nucleation (Vali, 2008; Zuberi et al., 2001). A pre-activation has also been observed for particles cooled to temperatures below $236 \mathrm{~K}$ and exposed to an environment with $S_{\text {ice }}<1$ in order to explicitly avoid initial ice formation (Fukuta, 1966; Higuchi and Fukuta, 1966). Even at relative humidities below the saturation value, water might condense in the capillaries of wettable solid particles. The condensed water might then freeze at $T<236 \mathrm{~K}$, again yielding an ice embryo capable of improving the ice nucleation ability of the particles. Finally, various organic substances suspended in water could be activated entirely in the liquid phase (Edwards and Evans, 1971; Evans, 1967), just by cooling the suspensions below a critical temperature upon which, according to the interpretation by Edwards and Evans (1971), the layer of adsorbed water molecules on the surface of the particles transforms from a disordered state into an ordered state, the latter being a better substrate for the nucleation of ice. 
Concerning expansion run 1 with the sodium oxalate crystals, it is obvious that the improvement of their ice nucleability goes along with the formation of the liquid phase and the subsequent re-crystallisation of the particulates. As discussed above, the crystals apparently do not get completely dissolved on the timescale of the experiment because otherwise the continuous increase in $f_{\text {ice }}$ from $t=90 \mathrm{~s}$ to $270 \mathrm{~s}$ due to condensation freezing would not have been monitored. But at least the outer particle shell might have been partially dissolved during the droplet activation. Obviously, the subsequent re-crystallisation after the droplet evaporation must have left behind a crystalline structure that is more susceptive to deposition mode ice nucleation than the structure generated by the initial crystallisation of the injected, supersaturated sodium oxalate solution droplets. After the evaporation of the ice crystals generated during run 1 , the modified crystals were probed in a succeeding expansion run that was directly started at reduced pressure, i.e., without refilling the AIDA chamber with dry, synthetic air to ambient pressure (Fig. 8, right panel). In run 2, the modified sodium oxalate crystals act as efficient ice nuclei in the deposition mode with $S_{\text {ice, crit }}=1.06$ and $f_{\text {ice }}=0.07$, now being almost as ice active as the slightly larger oxalic acid dihydrate crystals from run 1 in Exp. 1 (Fig. 4). As clearly shown by the comparison of the AIDA records from the two succeeding expansion cycles of Exp. 4, the saturation ratio always remains below water saturation during run 2 and the temporary drop in the depolarisation ratio due to the formation of spherical water droplets that was observed in run 1 does not occur in run 2 . Note that the number concentration of nucleated ice crystals in run 2 is by more than a factor of two higher than in run 1 . This underlines that the observed improvement of the ice nucleability cannot be solely related to those sodium oxalate crystals that have nucleated ice in the first expansion run but must be ascribed to the droplet activation event where almost all particles have been involved. The sodium oxalate particles retain their high ice nucleability when the AIDA chamber is refilled with dry, synthetic air to ambient pressure after the end of expansion run 2 (at $t=600 \mathrm{~s}$, see right panel of Fig. 8). During recompression, $S_{\text {ice }}$ temporarily dropped to a minimum value of about 0.61 . $S_{\text {ice }}$ values lower than 0.65 were maintained over a period of about $900 \mathrm{~s}$ during refilling. Expansion run 3 that was started after reaching ambient pressure closely reproduced the AIDA records from run 2 in terms of the critical threshold relative humidity and ice-active fraction, yielding $S_{\text {ice, } \text { crit }}=1.07$ and $f_{\text {ice }}=0.06$.

In three consecutive expansion cooling cycles that were performed during Exp. 5 with the smaller-sized sodium oxalate crystals, a similar improvement in the ice nucleation ability was observed. Again, the sodium oxalate particles could be notably activated by a first expansion run where the relative humidity had increased up to water saturation and a cloud of supercooled water droplets had formed. In the two following expansion runs, early deposition mode ice nucleation could be observed, provoking that saturation with re- spect to supercooled water was no longer reached in the later course of these expansions. The threshold saturation ratio $S_{\text {ice,crit }}$ for deposition ice nucleation in run 2 and run 3 of Exp. 5 was about 1.15, i.e., somewhat higher in comparison with the larger crystals probed in Exp. 4. Also, the ice-active fraction was only about $0.05 \%$, in accordance with the sizedependency of $f_{\text {ice }}$ for oxalic acid dihydrate particles that has been observed in experiments 1,2 , and 3 . In summary, the findings from the ice nucleation experiments with anhydrous sodium oxalate particles imply that the high ice-nucleability of oxalic acid dihydrate that has been observed so far might not be primarily related to its hydrogen-bonded crystal lattice because also the water-free sodium oxalate crystals could be modified to quite efficient deposition mode ice nuclei. Furthermore, we will now address two experiments that do not fit into the overall picture of highly deposition mode ice-active oxalic acid dihydrate crystals which has been outlined until now.

\subsection{Ice nucleation ability of oxalic acid dihydrate, crystallisation at $T>244 \mathrm{~K}$}

Having observed a fast crystallisation of highly supersaturated oxalic acid solution droplets to oxalic acid dihydrate at $T=244 \mathrm{~K}$, we decided to inject the aerosol particles into AIDA at a much higher temperature $(T=266 \mathrm{~K})$ in order to probe whether less concentrated solution droplets would remain in a supercooled liquid state or whether oxalic acid dihydrate crystals of a different surface structure and ice nucleability would nucleate under the modified saturation conditions. The initial relative humidity with respect to supercooled water for the crystallisation and ice nucleation experiments started at $T=266 \mathrm{~K}$ was typically about $89 \%$, yielding an approximate equilibrium solute concentration of only $35 \mathrm{wt} \%$ oxalic acid in comparison with about $67 \mathrm{wt} \%$ for an AIDA temperature of $244 \mathrm{~K}$ (see Fig. 1 and the discussion in Sect. 3.1). The top panel of Fig. 9 depicts the temporal evolution of the depolarisation ratio after spraying an aqueous solution of $4 \mathrm{wt} \%$ oxalic acid into the cooled cloud chamber with the dispersion nozzle at time zero for a time period of about $10 \mathrm{~s}$ (Exp. 6). The AIDA gas temperature is shown as a comparison. For a very long observation time of almost $3 \mathrm{~h}(t=10000 \mathrm{~s}$, first green line in Fig. 9), $\delta$ remains constant at a value of 0.02 , indicating that the injected droplets indeed initially remained in a supersaturated liquid state. Note that a small background value for $\delta$ of typically $0.02-0.03$ is observed even when only spherical droplets are present in the chamber. This is a result of Rayleigh scattering by air molecules, an imperfect alignment of the polarisers in the optical set-up, and a less than $100 \%$ horizontal or vertical polarisation of the laser light. At later times, however, the depolarisation ratio starts to increase although the chamber temperature was still kept constant at $266 \mathrm{~K}$. This delayed onset of crystallisation is most probably the result of a changing solute concentration. As indicated in Sect. 2, the 
spraying technique was an efficient method to inject substantial aerosol mass loadings into AIDA within a few seconds. Because a dilute oxalic acid solution was sprayed in, excess water released from the evaporation of the solution droplets provoked a sudden rise in the relative humidity from 89 to 96\% after aerosol injection, as monitored by TDL absorption spectroscopy (red trace in the bottom panel of Fig. 9). It took about $10000 \mathrm{~s}$ to dissipate the excess of water vapour and to restore the initial relative humidity of $89 \%$. Due to the small negative slope of the ice-melting point curve at higher temperatures, the comparably slight increase of $\mathrm{RH}_{\text {liq }}$ from 89 to $96 \%$ leads to a substantial change in the equilibrium concentration of the oxalic acid solution droplets from about 35 to $15 \mathrm{wt} \%$ (Fig. 1). Note that these estimated acid concentrations are affected by a large uncertainty because the small negative slope of the ice-melting point curve also provokes that the comparatively small uncertainty of about $\pm 3 \%$ in the TDL humidity measurements is transformed into a much larger uncertainty in the aerosol composition. Taking into account these uncertainties, the injected aqueous droplets initially attain an oxalic acid concentration in the range from 3 to $25 \mathrm{wt} \%$ and then slowly lose water and concentrate to 28-42 wt\% within the first 10000 seconds of the crystallisation experiment. The shrinking of the solution droplets due to the loss of water is nicely mimicked by the decrease in the forward-to-backward scattering ratio $\frac{I_{\text {for }}}{I_{\text {back,par }}+I_{\text {back,per }}}$ from the laser light scattering measurements, shown as black trace in the lower panel of Fig. 9.

Oxalic acid solution droplets with $<(35 \pm 7)$ wt $\%$ solute concentration can thus be maintained in AIDA for some hours in a supercooled liquid state without any detectable crystallisation, either homogeneously or heterogeneously on suited active sites in the chamber interior. This is in agreement with the result from Zobrist et al. (2006) that emulsified solutions of up to $20 \mathrm{wt} \%$ oxalic acid did not crystallise homogeneously upon cooling. Only for a sufficiently high solute concentration of about $28-42 \mathrm{wt} \%$, the crystallisation of the solution droplets becomes detectable on the timescale of the AIDA experiment. To identify the chemical nature of the crystallised particulates, FTIR extinction spectra were again recorded at different time steps during the crystallisation experiment (see small vertical bars on the time scale in the top panel of Fig. 9 and the corresponding spectra in Fig. 10). Spectrum (a) features a broad extinction band in the $\mathrm{O}-\mathrm{H}$ stretching regime, characteristic of aqueous oxalic acid solution droplets, as well as a pronounced light scattering contribution at non-absorbing wavenumbers $>3600 \mathrm{~cm}^{-1}$. Using the optical constants of pure water in this wavenumber regime in a Mie fitting procedure, the diameter of the oxalic acid droplets can be estimated to be about $1 \mu \mathrm{m}$. This is much larger than the droplet size simultaneously measured by the SMPS instrument (panel d, Fig. 3) because this device is not operated at the high relative humidity that is prevalent in the chamber interior and thus a significant shrinking of the

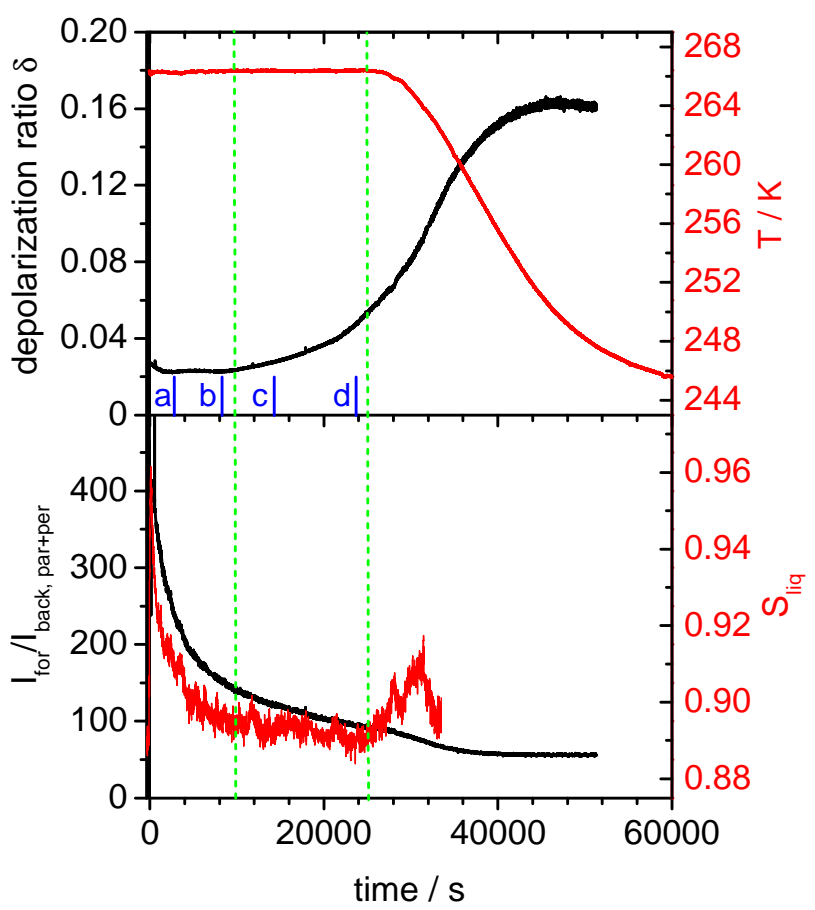

Fig. 9. Time series of the backscattering linear depolarisation ratio $\delta$ (top panel, black line), the AIDA gas temperature (top panel, red line), the forward-to-backward scattering ratio (bottom panel, black line), and the saturation ratio with respect to supercooled water (bottom panel, red line) after spraying an aqueous solution of $4 \mathrm{wt} \%$ oxalic acid into the chamber at time zero (Exp. 6). The small blue bars on the time scale in the top panel indicate the times of the infrared spectra recordings that are shown in Fig. 10.

particles size due to evaporation of water takes place. Note that the FTIR retrieval result is also somewhat ambiguous because the particle size is at the lower size limit for which a unique retrieval result for the particle size distribution can be inferred, i.e., a set of different values for the mode width and median diameter of the particle size distribution might satisfy the same optical data (Echle et al., 1998). Nonetheless, the retrieved particle size in combination with the size distribution measurement from Fig. 3d suggest that the injected oxalic acid solution droplets were initially very dilute, i.e., corresponding to the lower limit of the estimated range of acid concentrations from 3 to $25 \mathrm{wt} \%$. An accurate determination of the aerosol composition would necessitate temperatureand composition-dependent infrared optical constants for oxalic acid.

Spectrum (b) still bares the spectral habit of completely liquid droplets, however revealing a reduced intensity in the $\mathrm{O}-\mathrm{H}$ absorption and high-wavenumber scattering regime due to loss of particle water and the associated decrease in particle size. Spectra (c) and (d) bare the first signatures of an ongoing crystallisation process, as can be seen more closely in the two spectral subsets shown in the bottom part of Fig. 10. 

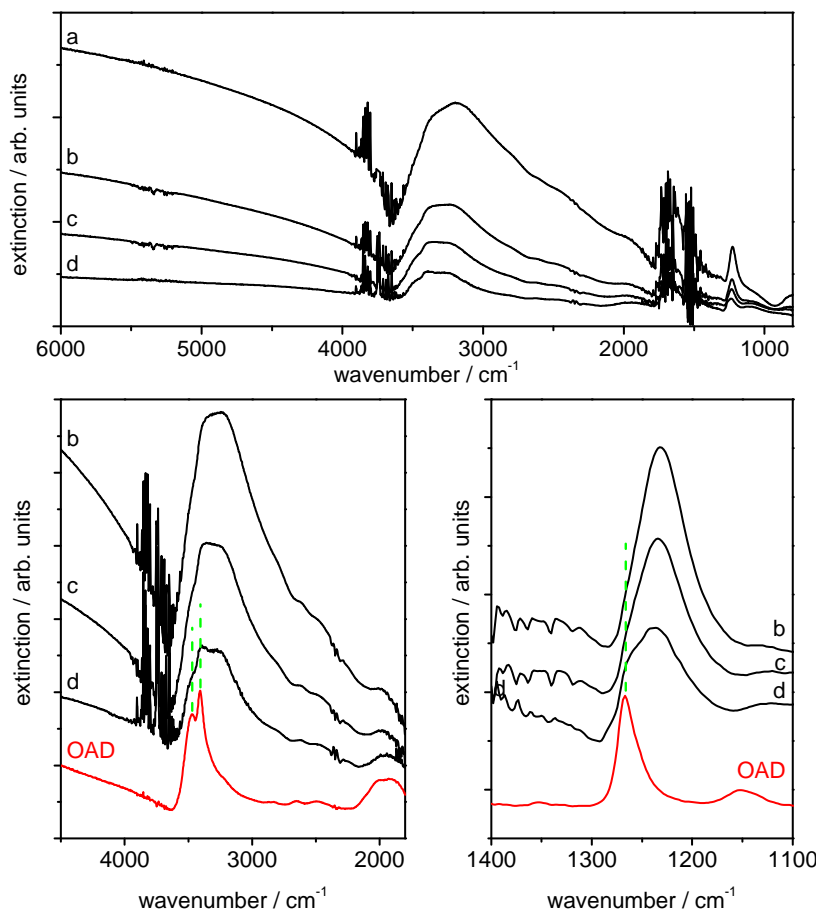

Fig. 10. Infrared extinction spectra of crystallising oxalic acid solution droplets recorded at different time steps during Exp. 6, as indicated by the vertical blue bars in Fig. 9. The two bottom panels show expanded views in the regime of the $\mathrm{O}-\mathrm{H}$ and $\mathrm{C}-\mathrm{O}$ stretching modes and include a reference spectrum of pure oxalic acid dihydrate particles (red trace, corresponding to spectrum e in Fig. 4). See text for details. Note that only an incomplete background subtraction of the absorption lines of gaseous water could be achieved due to the high AIDA temperature and the correspondingly high water vapour concentration.

Within the O-H stretching regime, two shoulders appear on the high-wavenumber tail of the liquid water extinction band, coinciding with the peak positions of the doublet signature in oxalic acid dihydrate. In the same way, a shoulder is formed at $1270 \mathrm{~cm}^{-1}$ in the regime of the $\mathrm{C}-\mathrm{O}$ stretching mode, further evidencing that oxalic acid dihydrate particles have started to crystallise from the supersaturated aqueous solution droplets. As discussed above, the experiments were not aimed at deriving crystallisation rates because it was not possible to determine the number concentration of crystallised particles within the population of still unfrozen solution droplets. After having positively identified oxalic acid dihydrate as the crystallisation product, the chamber was cooled overnight to $244 \mathrm{~K}$ to probe the ice nucleation potential of the crystallised particulates (cooling started at $t=25000 \mathrm{~s}$, see second green line in Fig. 9). About $20000 \mathrm{~s}$ after the start of cooling, the entire aerosol population had crystallised, as indicated by a constant depolarisation ratio of 0.16 .
After homogeneous temperature and humidity conditions had established in the chamber interior at $T=244 \mathrm{~K}$ the next morning, two subsequent expansion runs were started (Fig. 11, left panel). In contrast to all previously reported expansion runs, the oxalic acid dihydrate particles generated during Exp. 6 did not act as deposition mode ice nuclei before reaching an ice saturation ratio of about 1.3 at $t=85 \mathrm{~s}$ which is close to water saturation. The first 200 seconds of the expansion run are shown in expanded view in the right panel of Fig. 11. As can be seen by the short-time decrease in the depolarisation ratio after $t=85 \mathrm{~s}$, ice formation coincides with the temporary formation of a cloud of supercooled water droplets. These small-sized cloud droplets do not extend into the measurement range of the OPC2 but can be seen in a series of infrared extinction spectra that is shown in Fig. 12. The spectra were recorded at a time interval of 10 $\mathrm{s}$, beginning with spectrum (a) at $t=85 \mathrm{~s}$, i.e., immediately before the temporary decrease in the depolarisation ratio occurred. Spectrum (b) features a pronounced extinction band at $3300 \mathrm{~cm}^{-1}$ due to liquid water droplets. The major part of the spectral signature can be accurately reproduced with a Mie fit using the optical constants of supercooled water (red line), yielding a median droplet diameter of about $1.5 \mu \mathrm{m}$ (Wagner et al., 2005a; Zasetsky et al., 2005). Only the small extinction minimum at $950 \mathrm{~cm}^{-1}$ in spectrum (b) cannot be accurately mimicked by the Mie fit because this signature is due to the first ice crystals that have nucleated. This feature gains in intensity in the subsequent spectra recordings. Additionally, a second extinction minimum at $3500 \mathrm{~cm}^{-1}$ is formed. These two extinction minima are called Christiansen bands and are the typical infrared spectral signature of ice crystals with sizes larger than at least 5-6 $\mu \mathrm{m}$ (Arnott et al., 1995). Spectrum (d) can only be accurately reproduced with a bimodal fit, employing one mode for water droplets and a second mode for ice crystals. Spectrum (e) recorded at $t=125 \mathrm{~s}$ finally represents a pure cloud of about $10 \mu \mathrm{m}$ sized ice crystals, as retrieved from a unimodal fit using appropriate low-temperature refractive indices for ice (Zasetsky et al., 2005).

Three different mechanisms can be discussed to explain the observed ice nucleation behaviour in the first expansion run of Exp. 6. Firstly, the oxalic acid dihydrate crystals may have acted as condensation mode ice nuclei because the onset of ice formation apparently coincides with the formation of the cloud of supercooled water droplets. However, this would not explain that the ice particle number concentration still increases after the water cloud has completely glaciated at $t=125 \mathrm{~s}$ via the Bergeron-Findeisen process (see fourth panel in Fig. 11). One might also speculate that a fraction of the oxalic acid dihydrate particles has acted as deposition mode ice nucleus with a threshold $S_{\text {ice,crit }}$ value so close to water saturation that less ice-active particles have simultaneously become activated to water droplets. This would explain that ice crystals continue to nucleate after $t=125 \mathrm{~s}$ because the environment is still supersaturated with respect to 

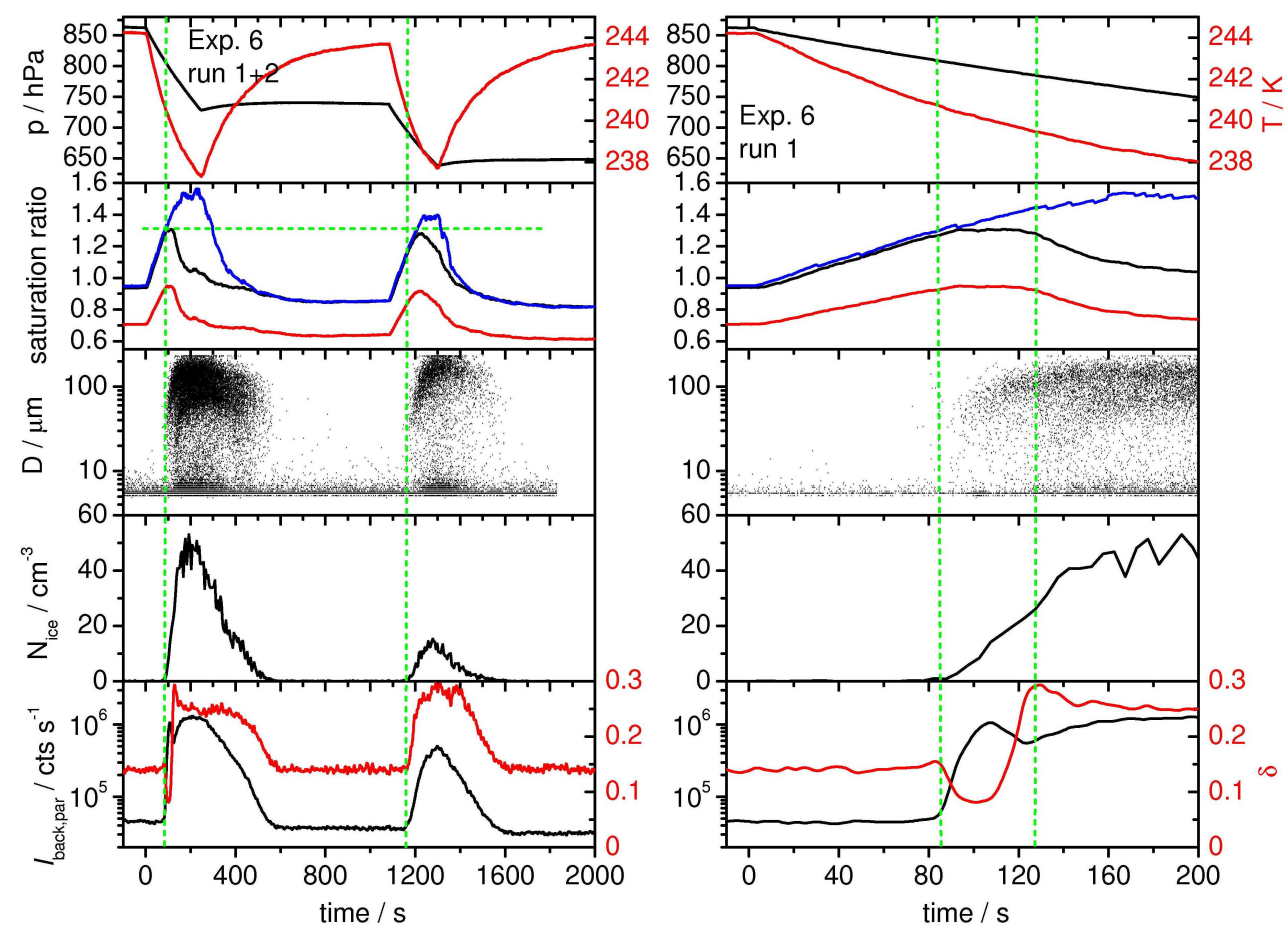

Fig. 11. Time series of various AIDA records during the expansion cooling cycles from Exp. 6. The left panel covers the complete time period of expansion runs 1 and 2 whereas the right panel shows an expanded view of the first $200 \mathrm{~s}$ from run 1 .

ice. Finally, the oxalic acid dihydrate crystals may just have behaved in a similar manner as the sodium oxalate particles in the first expansion run of Exp. 4 (Fig. 8). Some crystals have acted as condensation mode ice nuclei and the ice particle number concentration continues to increase because the crystalline structure of other oxalic acid dihydrate particles was modified by the droplet activation and evaporation cycle. Thus, when again directly exposed to an ice supersaturated environment after the evaporation of the cloud water, these modified particles could now act as deposition mode ice nuclei. The scatter plot from the OPC2 indeed indicates that a distinct second mode of initially smaller ice crystals starts to nucleate at $t=125 \mathrm{~s}$ (second green line in the right panel of Fig. 11). Note that homogeneous freezing cannot account for this second ice crystal mode because the gas temperature was still above $239 \mathrm{~K}$ at $t=125 \mathrm{~s}$. Based on this interpretation, the first expansion runs of Exp. 4 and Exp. 6 would only differ by the overall time period where a stable mixed-phase cloud is present in AIDA. As the absolute number concentration of ice crystals formed by condensation freezing is much lower in Exp. 4 compared to Exp. 6, the mixed-phase cloud persists for a much longer period of time. This explanation would also account for the modified ice nucleation behaviour that is displayed in the second expansion run of Exp. 6. Run 2 was started at $t=1080 \mathrm{~s}$ after all ice crystals from the previous expansion run had evaporated. In the course of expansion cooling, a pure ice cloud is formed by deposition mode ice nucleation at $S_{\text {ice, crit }}=1.20 . S_{\text {ice, } \max }$ remains below water saturation in the later course of the expansion, explaining that a temporary decrease in $\delta$ due to a cloud droplet activation is not observed during run 2 . The two succeeding expansion runs thereby reveal the same change in the ice nucleation behaviour that has been previously observed for the two repetitive expansion cooling cycles in Exp. 4 with sodium oxalate particles.

The results from Exp. 6 clearly differ from the previous finding that oxalic acid dihydrate particles are highly efficient ice nuclei in the deposition mode with a threshold ice saturation ratio below 1.1 even for nanosized crystallites. The particles generated during Exp. 6 were initially only ice-active in the condensation mode. Some particles were then modified to become ice-active in the deposition mode, however

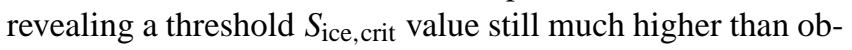
served in Exp. 1, 2, and 3. Most likely, the discrepancy in the ice nucleation behaviour between the various experiments is caused by differences in the crystal structure and morphology of the oxalic acid dihydrate particles. The impact of surface microstructure of crystalline solids on their heterogeneous freezing ability is well documented in the literature, as for example in the case of ammonium sulphate particles. Zuberi et al. (2001) have demonstrated that the thermal history of solid ammonium sulphate cores imbedded in aqueous particles affected their morphology and heterogeneous ice nucleability. A crystalline core composed of many microcrystals, 


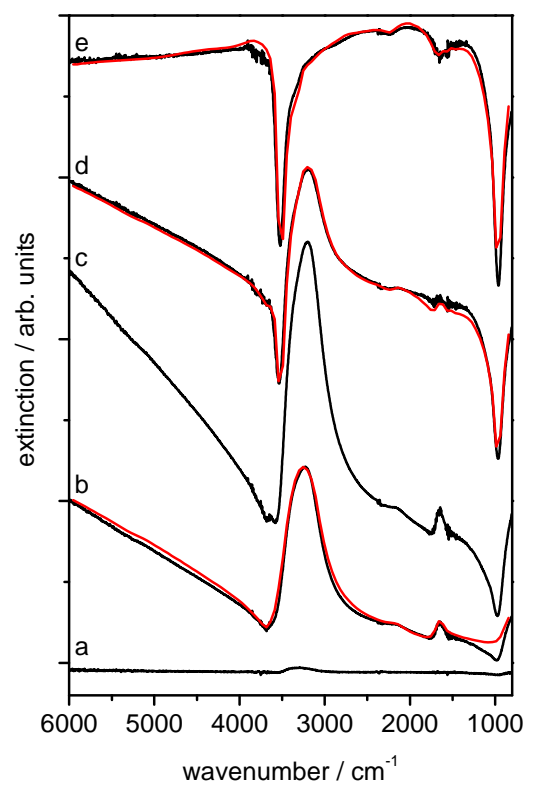

Fig. 12. Infrared extinction spectra recorded from $t=85 \mathrm{~s}$ (spectrum a) to $t=125 \mathrm{~s}$ (spectrum e) at a $10 \mathrm{~s}$ time interval during expansion run 1 from Exp. 6 (black lines). Note that a new background spectrum had to be recorded prior to these measurements. This was necessary because the cooling of the AIDA chamber from 266 to $244 \mathrm{~K}$ (see Fig. 9) induced a misalignment of the White-cell system. The extinction features due to the crystallised oxalic acid dihydrate particles (see Fig. 10) are therefore not visible. Various computed extinction spectra that best-fitted the measurements are shown as red lines. Spectra $b$ and e were fitted by unimodal log-normal distributions of either supercooled water droplets or ice crystals, respectively. The latter were modelled as circular cylinders of aspect ratio 0.7 (Wagner et al., 2006). The mixed-phase cloud scenario represented by spectrum d was fitted by two log-normal modes, with one mode for the water droplets and the other for the ice crystals.

generated by warming a completely frozen $\left(\mathrm{NH}_{4}\right)_{2} \mathrm{SO}_{4}-\mathrm{H}_{2} \mathrm{O}$ solution droplet only slightly above the eutectic temperature to induce the melting of ice, acted as a very efficient ice nucleus, i.e., the heterogeneous ice-freezing temperature was close to the eutectic temperature and $S_{\text {ice,crit }}$ close to 1 . If instead the crystalline core was composed of only one or two large crystals, prepared by temporarily raising the temperature of the particle to a higher conditioning temperature, the heterogeneous freezing temperature was close to the homogeneous freezing temperature. In the same way, Shilling et al. (2006) have detected a high deposition mode ice activity for polycrystalline ammonium sulphate particles whereas in other studies, as discussed by the authors, subeutectic deliquescence has been observed. Concerning our present results, one might therefore speculate that the rapid crystallisation or nucleation of the oxalic acid dihydrate particles during Exp. 1, 2, and 3 has led to the formation of a surface microstructure with numerous defects, resulting in a high deposition mode ice activity. During Exp. 6, where the oxalic acid

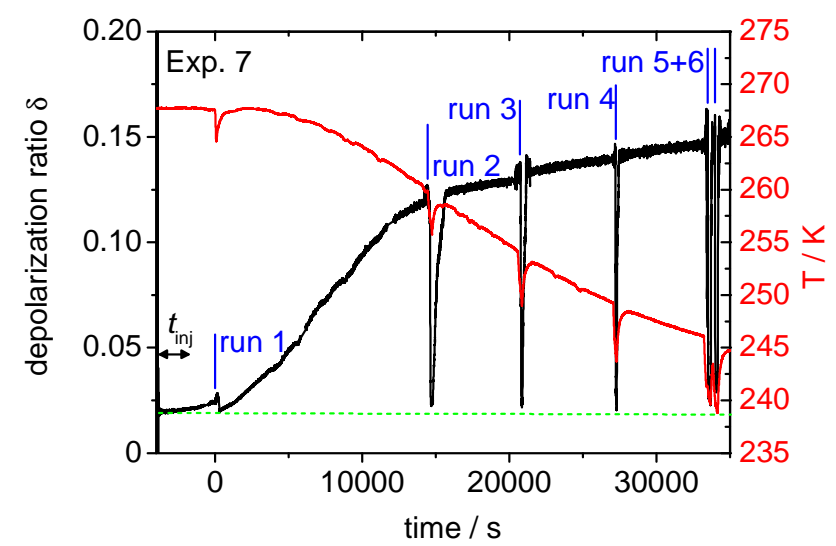

Fig. 13. Temporal evolution of the backscattering linear depolarisation ratio $\delta$ (black line) and the AIDA gas temperature (red line) during Exp. 7 that was started by adding aqueous oxalic acid solution droplets to the AIDA chamber at $266 \mathrm{~K}$ with an atomiser. In the course of the experiment, the ice nucleation ability of the aerosol particles was probed in six expansion cooling cycles, as indicated by the vertical blue bars. The horizontal green line denotes the background value for the depolarisation ratio of about 0.02 that is typically observed even if only spherical particles are present.

dihydrate particles were formed from less supersaturated oxalic acid solution droplets at a higher temperature and were allowed to slowly grow by mass transfer from still unfrozen solution droplets over a very long time scale of about $12 \mathrm{~h}$, see appendix A in Zobrist et al. (2006), more regular crystals with less defects and a correspondingly lower ice nucleability might have formed. That different crystallisation conditions might strongly influence the resultant particle morphology has also been demonstrated in earlier AIDA investigations on the formation of nitric acid dihydrate crystals, either generated by shock freezing of a $\mathrm{HNO}_{3} / \mathrm{H}_{2} \mathrm{O}$ gas mixture or by homogeneous nucleation from supercooled aqueous nitric acid solution droplets where the nucleated nitric acid dihydrate crystals could slowly grow in a supersaturated environment for a period of several hours (Wagner et al., 2005b). With our present experimental set-up, the hypothesis of a different surface microstructure of the oxalic acid dihydrate crystals cannot be verified. In future AIDA campaigns, it is planned to fully explore the potential of the SID3 detector to distinguish between smooth and rough surfaces of larger ice crystals by the analysis of their angular scattering patterns. But again, it is not clear whether such distinction would also be achievable for only about $1-2 \mu \mathrm{m}$-sized aerosol particles. Probing the particle morphology of deposited crystals by environmental scanning electron microscopy might be another option in future crystallisation experiments.

We will conclude the discussion with another example for the high diversity of the ice nucleation behaviour of oxalic acid dihydrate. In Exp. 7, aqueous solution droplets of oxalic acid were again added to the AIDA chamber at about 

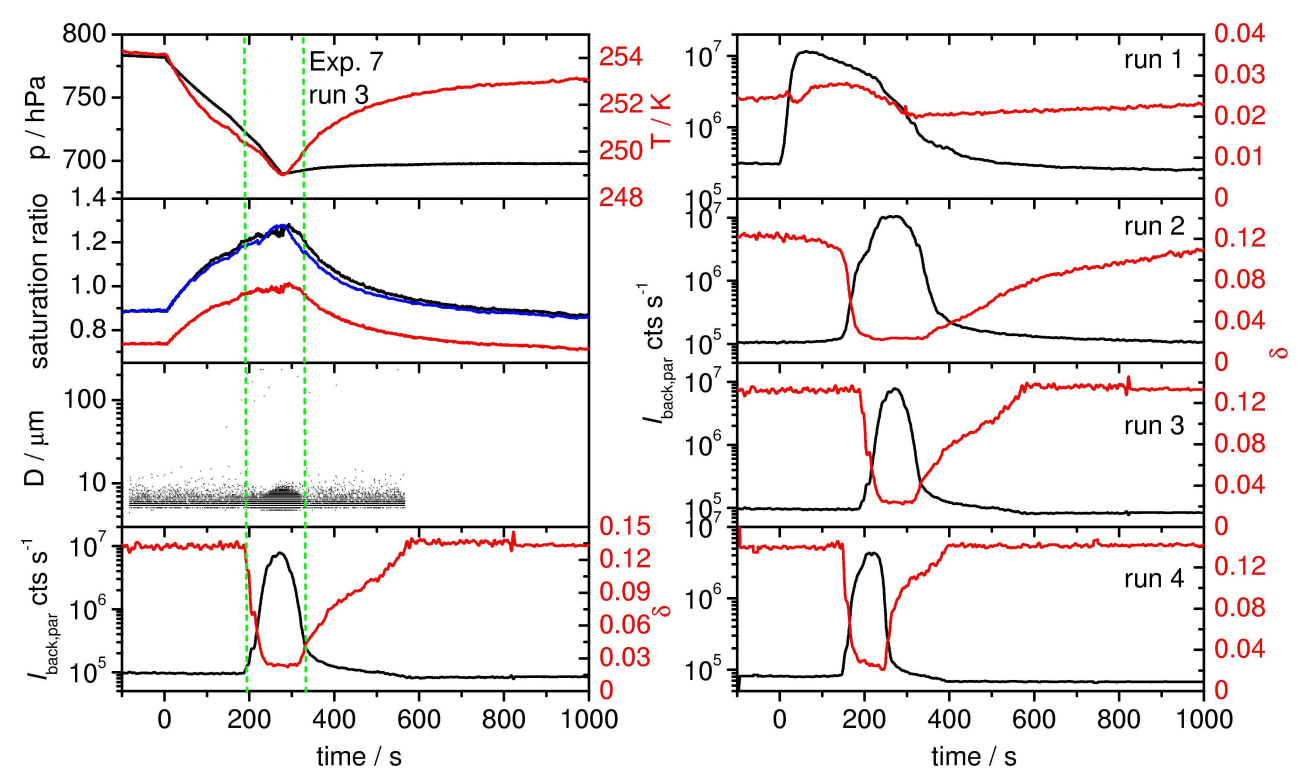

Fig. 14. Left panel: Time series of various AIDA records during expansion cooling run 3 from Exp. 7 (see also Fig. 13). Because almost no ice crystals have formed, the sub-panel containing the ice-active fraction or ice particle number concentration is not shown. Right panel: Compilation of the backscattering intensities and depolarisation ratios recorded during the expansion runs 1-4 from Exp. 7. In each graph, time zero denotes the start of pumping. Only for the first run, time zero corresponds to $t=0$ on the time scale of Fig. 13 .

$266 \mathrm{~K}$, this time using the atomiser. Due to the much lower mass throughput of this device in comparison with the dispersion nozzle used in Exp. 6, the injection period was about $30 \mathrm{~min}$ (Fig. 13). The relative humidity with respect to supercooled water did not increase during aerosol addition, but was stable between 89 and $90 \%$. Hence, a small but immediate increase in the depolarisation ratio could be observed after adding the aerosol (black trace in Fig. 13), indicating that the onset of crystallisation of the injected solution droplets was not delayed due to a temporary increase in the relative humidity as in Exp. 6. About $30 \mathrm{~min}$ after the end of aerosol addition, the particles were probed in a first expansion run (time zero in Fig. 13). During the expansion, the aerosol particles were activated to cloud droplets and the depolarisation ratio temporarily got back to its initial background value, pointing to the deliquescence of the particles that had already crystallised. After expansion run 1, the AIDA chamber was slowly cooled to $244 \mathrm{~K}$ (red trace in Fig. 13), going along with an increase in the depolarisation ratio to a final value of about 0.15 . As already outlined in the caption of Fig. 12, a variation of the temperature of the AIDA vessel leads to a change in the alignment of the White-cell mirrors of the in situ infrared extinction measurements. This means that the initially recorded background spectrum is no longer a suited reference. The chemical nature of the crystallised particulates can thus not be verified in Exp. 7, however, there is no reason to assume that not again oxalic acid dihydrate particles have formed. Already before reaching $T=244 \mathrm{~K}$, the crystallised particles were probed on their ice nucleabil- ity in three expansion runs started at 260,254 , and $249 \mathrm{~K}$. The observed behaviour was similar in all cooling cycles and, therefore, only AIDA records from run 3 are shown in the left panel of Fig. 14. As obvious from the scatter plot of the OPC2, only very few large ice crystals with an optical diameter larger than $10 \mu \mathrm{m}$ were formed. The ice particle number concentration was clearly below $0.1 \mathrm{~cm}^{-3}$, meaning that these crystals might have also nucleated on the few background particles that were present in the chamber before adding the oxalic acid aerosol. Instead of forming an ice cloud, the aerosol particles were activated to a droplet cloud when reaching water saturation at $t=190 \mathrm{~s}$. The droplet diameters overlap with the apparent diameters of the aspherical oxalic acid dihydrate particles and the droplet cloud, therefore, only appears as a denser point cloud in the OPC2 scatter plot between $t=190$ and $330 \mathrm{~s}$ (marked by the two vertical green lines). After the evaporation of the supercooled cloud droplets at $t=330 \mathrm{~s}$, the temporarily reduced depolarisation ratio regains its value from the start of pumping within less than $300 \mathrm{~s}$. This indicates that at lower temperatures the oxalic acid dihydrate crystals do not get completely dissolved on the typical time scale of an expansion experiment, meaning that at least a small solid core remains unsolved and causes the rapid re-crystallisation of the particles. In previous literature studies, the dissolution kinetics of oxalic acid dihydrate have only been investigated at room temperature in $\mathrm{HCl}(0.1 \mathrm{~N})$ as dissolution medium under hydrodynamic conditions that are not comparable to the present experiments (Carstensen and Dali, 1999; Carstensen and Patel, 


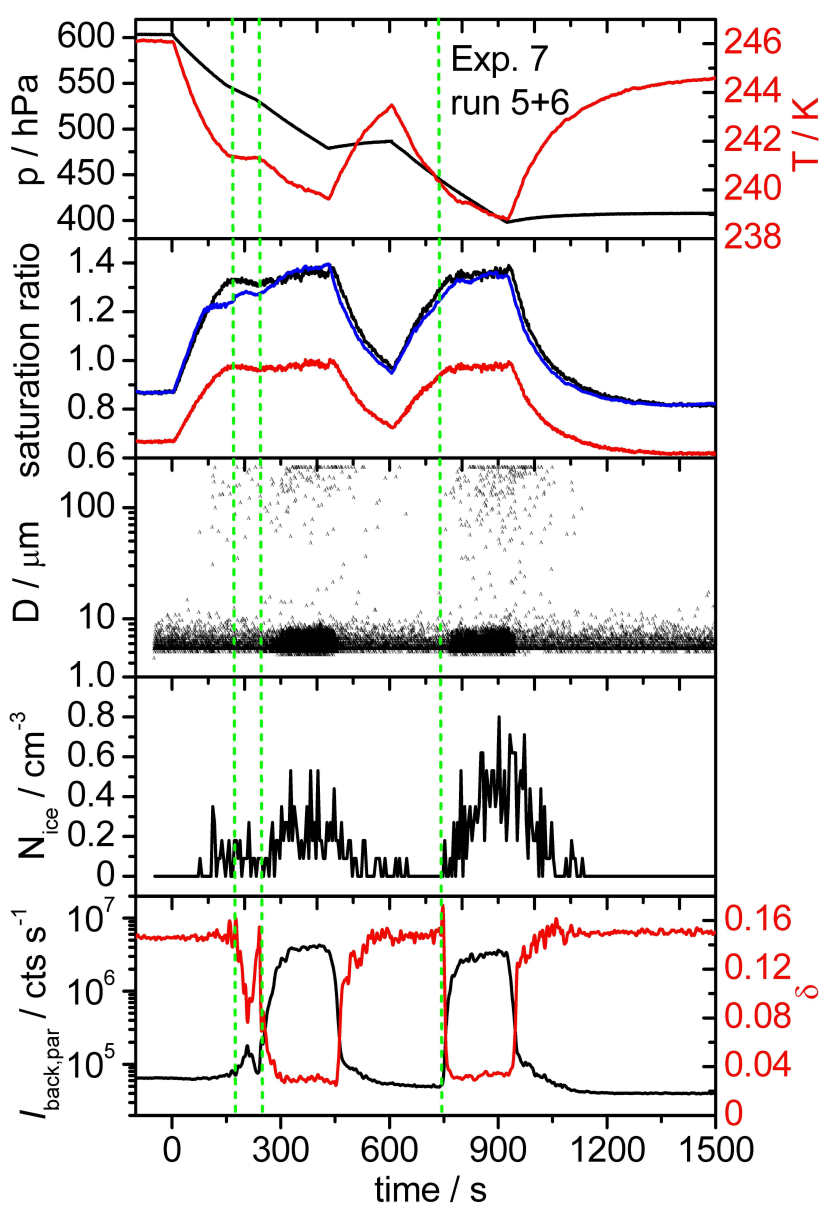

Fig. 15. Time series of various AIDA records during the expansion cooling runs 5 and 6 from Exp. 7 (see also Fig. 13).

1975). Time series of the depolarisation ratios recorded during the expansion runs 1-4 are compared in the right panel of Fig. 14. The compilation shows that the time period to recover the initial value of $\delta$ after the evaporation of the droplet cloud continually decreases with decreasing AIDA temperature.

The oxalic acid dihydrate particles generated during Exp. 7 do not exhibit any heterogeneous ice nucleation potential at $T \geq 249 \mathrm{~K}$. After expansion run 4, the crystals are further cooled to $244 \mathrm{~K}$, i.e., to a temperature where all previously generated oxalic acid dihydrate particles showed considerable ice-nucleability in either the condensation mode (Exp. 6, first run) or deposition mode (Exp. 1 and 2; Exp. 6, second run). The AIDA records from two succeeding expansion runs started at about $244 \mathrm{~K}$ during Exp. 7 are shown in Fig. 15. Surprisingly, also at the lower temperature the ice nucleation potential of the oxalic acid dihydrate particles is very poor. Only about $0.1 \mathrm{~cm}^{-3}$ ice particles were formed by deposition nucleation before water saturation was reached at $t=240 \mathrm{~s}$ (second vertical green line). Note that already $70 \mathrm{~s}$ earlier $(t=170 \mathrm{~s}$, first green line) the relative humidity had just approached water saturation, leading to the first drop in the depolarisation ratio. But unintentionally, the pumping speed was reduced at this time, leading to a slight decrease in the saturation ratio and to the evaporation of the droplets that just had formed. Only after increasing the pumping speed again, the entire aerosol population was activated to cloud droplets at $t=240 \mathrm{~s}$. Also by subsequent condensation freezing, only a very low number concentration of ice crystals was generated, amounting to about $0.3 \mathrm{~cm}^{-3}$ in run 5 and $0.5 \mathrm{~cm}^{-3}$ in run 6 that was immediately started after the cloud particles from the first run had evaporated. As a comparison, the aerosol number concentration prior to pumping was about $9500 \mathrm{~cm}^{-3}$. Thus, oxalic acid dihydrate particles that have gone through several partial dissolution and re-crystallisation steps at warmer temperatures are much poorer ice nuclei when cooled to $244 \mathrm{~K}$ than crystals that were probed without preceding droplet activation runs (Exp. 6). Also, the first droplet activation at $244 \mathrm{~K}$ (run 5) does not notably change the ice nucleation potential in contrast to the behaviour observed in the two repetitive expansion runs from Exp. 4 and 6. One cannot completely exclude that a species different from crystalline oxalic acid dihydrate, like anhydrous crystals, amorphous particles, or the recently discovered dimorphic sesquihydrates of oxalic acid (Wenger and Bernstein, 2007), has been formed during the various droplet activation runs in Exp. 7 due to the lack of information from the infrared spectra recordings. Only the formation of glassy particles can most probably be ruled out due to the low molar mass of oxalic acid. According to the relationship found by Zobrist et al. (2008), the glass transition curve will intersect the ice melting-point curve at about $166 \mathrm{~K}\left(T_{g}^{\prime}\right)$ for solutes with a molar mass of $90 \mathrm{~g} \mathrm{~mol}^{-1}$; see Fig. 7 and Eq. (3) in their publication. Even when considering the estimated confidence interval of $\pm 25 \mathrm{~K}$ that reflects the sensitivity of $T_{g}^{\prime}$ to the chemical structure and hydrophilicity of a particular solute, the expected glass transition temperatures of oxalic acid solutions are well below the temperature range covered by our experiments. More likely, the modified ice nucleability that was observed in Exp. 7 is related to the high variability of the surface microstructure of the crystallised oxalic acid dihydrate particles that have been generated and cloud-processed in different ways. Thereby, this chemically simply-structured substance reveals a remarkable variability in its ice nucleation potential, which, just by comparing Figs. 5 and 15, ranges from very high deposition mode ice activity to very poor ice nucleation ability in both the deposition and condensation mode, making it difficult to find a suited parameterisation to represent its ice nucleation behaviour in a microphysical model. 


\section{Summary}

We have presented measurements on the heterogeneous ice nucleation ability of airborne oxalic acid dihydrate and sodium oxalate particles in the deposition and condensation mode at temperatures between 244 and $228 \mathrm{~K}$. The observed ice nucleation potential of the particles was strongly dependent on their crystallisation pathway. Crystallisation of highly supersaturated oxalic acid solution droplets at $T=244 \mathrm{~K}$ or nucleation from a gaseous oxalic acid/water mixture that was added to the AIDA chamber at $T=228 \mathrm{~K}$ yielded oxalic acid dihydrate crystals that proved to be highly efficient deposition mode ice nuclei. The threshold ice saturation ratio for ice nucleation was always below 1.1. The number fraction of ice-active aerosol particles ranged between 22 and $0.1 \%$, depending on temperature and particle diameter that was varied between 0.8 and $0.03 \mu \mathrm{m}$. This finding is in good agreement with recent measurements on ice formation via deposition nucleation on oxalic acid dihydrate particles that were deposited on a cold stage and, at first sight, points to a special role of oxalic acid within the group of other saturated dicarboxylic acids that have not been observed to be good ice nuclei, neither in the deposition nor immersion mode. In further crystallisation and ice nucleation experiments, however, oxalic acid dihydrate particles of partially much poorer ice nucleability were generated. In these experiments, the oxalic acid dihydrate particles crystallised from less supersaturated oxalic acid solution droplets at a higher temperature and were allowed to slowly grow in a supersaturated environment from still unfrozen aqueous oxalic acid solution droplets over a time period of many hours. Obviously, these conditions have led to a more regular surface microstructure with fewer defects that could have triggered ice nucleation as active sites. As a notable difficulty for predicting the ice nucleation behaviour of oxalic acid dihydrate, the ice nucleability was also dependent on whether the crystallised particles were subjected to preceding droplet activation and evaporation steps or not. Such behaviour was also observed for the second species investigated, namely sodium oxalate.

Concerning the atmospheric implication of our findings, the presented experiments are relevant to the scenario where by way of physical and chemical processing a coating layer of organic material may have formed on prevalent particulates such as soot and mineral dust. With the aid of the FTIR extinction measurements, we have demonstrated that oxalic acid in form of its dihydrate was generated under various conditions, i.e., by crystallisation of supersaturated oxalic acid solution droplets of different acid concentrations and by nucleation from a gaseous oxalic acid/air mixture. One might therefore assume that also coating layers of oxalic acid would consist of this species. Given the high variability of the heterogeneous ice nucleation potential of oxalic acid dihydrate, it is not straightforward to anticipate in which direction the ice nucleability of the pure compounds will be modified by the organic coating layer. On the one hand, some active mineral dust surfaces could become deactivated with an oxalic acid dihydrate coating of poor ice nucleation ability such as detected in Exp. 7. Such behaviour has recently been observed in AIDA experiments on the suppression of the ice nucleation ability of mineral dust particles by a coating layer of secondary organic matter from the products of the $\alpha$-pinene-ozone reaction (Möhler et al., 2008). But on the other hand, soot particles that in most previous laboratory studies have behaved as poor deposition mode ice nuclei at temperatures around $244 \mathrm{~K}$ could become more ice-active when coated with a layer of oxalic acid dihydrate that behaved similar to the crystals generated in Exp. 1, 2, and 3. We therefore consider addressing the effect of coating layers of solid dicarboxylic acids on the heterogeneous ice nucleability of soot or mineral dust particles in future chamber studies. Having taken into account that in the atmosphere oxalic acid dihydrate crystals might also be embedded in multicomponent aqueous solutions droplets, we have already performed a set of ice nucleation experiments with ternary solution droplets containing sodium chloride and sulphuric acid as third components in addition to oxalic acid and water. The results of these experiments on the immersion freezing potential of oxalic acid will be summarised in a forthcoming manuscript.

Acknowledgements. The authors are grateful to all members of the AIDA staff for their continuous support during the numerous successful measurement campaigns on ice nucleation which have been conducted at the chamber facility in the past decade. The work has been funded by the Helmholtz-Gemeinschaft deutscher Forschungszentren as part of the program "Atmosphere and Climate".

Edited by: T. Koop

\section{References}

Apelblat, A. and Manzurola, E.: Solubility of Oxalic, Malonic, Succinic, Adipic, Maleic, Malic, Citric, and Tartaric Acids in Water from $278.15 \mathrm{~K}$ to $338.15 \mathrm{~K}$, J. Chem. Thermodyn., 19, 317-320, 1987.

Archuleta, C. M., DeMott, P. J., and Kreidenweis, S. M.: Ice nucleation by surrogates for atmospheric mineral dust and mineral dust/sulfate particles at cirrus temperatures, Atmos. Chem. Phys., 5, 2617-2634, doi:10.5194/acp-5-2617-2005, 2005.

Arnott, W. P., Dong, Y. Y., and Hallett, J.: Extinction Efficiency in the Infrared (2-18 $\mu \mathrm{m})$ of Laboratory Ice Clouds - Observations of Scattering Minima in the Christiansen Bands of Ice, Appl. Opt., 34, 541-551, 1995.

Baustian, K. J., Wise, M. E., and Tolbert, M. A.: Depositional ice nucleation on solid ammonium sulfate and glutaric acid particles, Atmos. Chem. Phys., 10, 2307-2317, doi:10.5194/acp-10-23072010, 2010.

Bellamy, L. J. and Pace, R. J.: Hydrogen Bonding in Carboxylic Acids.1. Oxalic Acids, Spectrochim. Acta, 19, 435-442, 1963. 
Benz, S., Megahed, K., Möhler, O., Saathoff, H., Wagner, R., and Schurath, U.: T-dependent rate measurements of homogeneous ice nucleation in cloud droplets using a large atmospheric simulation chamber, J. Photochem. Photobiol. A, 176, 208-217, 2005.

Braban, C. F., Carroll, M. F., Styler, S. A., and Abbatt, J. P. D.: Phase transitions of malonic and oxalic acid aerosols, J. Phys. Chem. A, 107, 6594-6602, 2003.

Carlton, A. G., Turpin, B. J., Altieri, K. E., Seitzinger, S., Reff, A., Lim, H. J., and Ervens, B., Atmospheric oxalic acid and SOA production from glyoxal: Results of aqueous photooxidation experiments, Atmos. Env., 41, 7588-7602, 2007.

Carstensen, J. T. and Dali, M., Determination of mass transfer dissolution rate constants from critical time of dissolution of a powder sample, Pharm. Dev. Technol., 4, 1-8, 1999.

Carstensen, J. T. and Patel, M.: Dissolution Patterns of Polydisperse Powders - Oxalic Acid Dihydrate, J. Pharm. Sci., 64, 17701776, 1975.

Chebbi, A. and Carlier, P.: Carboxylic acids in the troposphere, occurrence, sources, and sinks: A review, Atmos. Env., 30, 42334249, 1996.

Clegg, S. L. and Seinfeld, J. H.: Thermodynamic models of aqueous solutions containing inorganic electrolytes and dicarboxylic acids at $298.15 \mathrm{~K}$. 1. The acids as nondissociating components, J. Phys. Chem. A, 110, 5692-5717, 2006.

Crahan, K. K., Hegg, D., Covert, D. S., and Jonsson, H.: An exploration of aqueous oxalic acid production in the coastal marine atmosphere, Atmos. Env., 38, 3757-3764, 2004.

Ebisuzaki, Y. and Angel, S. M., Raman Study of HydrogenBonding in Alpha and Beta Oxalic Acid Dihydrate, J. Raman Spectrosc., 11, 306-311, 1981.

Echle, G., von Clarmann, T., and Oelhaf, H.: Optical and microphysical parameters of the Mt. Pinatubo aerosol as determined from MIPAS-B mid-IR limb emission spectra, J. Geophys. Res. Atmos., 103, 19193-19211, 1998.

Edwards, G. R. and Evans, L. F.: The Mechanism of Activation of Ice Nuclei, J. Atmos. Sci., 28, 1443-1447, 1971.

Ervens, B., Feingold, G., Frost, G. J., and Kreidenweis, S. M.: A modeling study of aqueous production of dicarboxylic acids: 1. Chemical pathways and speciated organic mass production, J. Geophys. Res. Atmos., 109, D15205, doi:10.1029/2003JD004387, 2004.

Evans, L. F.: Ice Nucleation under Pressure and in Salt Solution, Trans. Faraday Soc., 63, 3060-3071, 1967.

Fukuta, N.: Activation of Atmospheric Particles as Ice Nuclei in Cold and Dry Air, J. Atmos. Sci., 23, 741-750, 1966.

Hartman, K. O. and Hisatsune, I. C.: The Kinetics of Oxalate Ion Pyrolysis in a Potassium Bromide Matrix, J. Phys. Chem., 71, 392-396, 1967.

Higuchi, K. and Fukuta, N.: Ice in Capillaries of Solid Particles and Its Effect on Their Nucleating Ability, J. Atmos. Sci., 23, 187-190, 1966.

Hinds, W. C.: Aerosol Technology, John Wiley \& Sons, Inc., New York, USA, Chapter 3, 42-74, 1999.

Hsieh, L. Y., Kuo, S. C., Chen, C. L., and Tsai, Y. I.: Origin of lowmolecular-weight dicarboxylic acids and their concentration and size distribution variation in suburban aerosol, Atmos. Env., 41, 6648-6661, 2007.

Hudson, P. K., Gibson, E. R., Young, M. A., Kleiber, P. D., and Grassian, V. H.: A newly designed and constructed instrument for coupled infrared extinction and size distribution measurements of aerosols, Aerosol. Sci. Tech., 41, 701-710, 2007.

Kanji, Z. A. and Abbatt, J. P. D.: Laboratory studies of ice formation via deposition mode nucleation onto mineral dust and nhexane soot samples, J. Geophys. Res. Atmos., 111, D16204, doi:10.1029/2005JD006766, 2006.

Kanji, Z. A., Florea, O., and Abbatt, J. P. D.: Ice formation via deposition nucleation on mineral dust and organics: dependence of onset relative humidity on total particulate surface area, Environ. Res. Lett., 3, 025004, doi:10.1088/1748-9326/3/2/025004, 2008.

Kawamura, K., Kasukabe, H., and Barrie, L. A., Source and reaction pathways of dicarboxylic acids, ketoacids and dicarbonyls in arctic aerosols: One year of observations, Atmos. Environ., 30, 1709-1722, 1996.

Kerminen, V. M., Ojanen, C., Pakkanen, T., Hillamo, R., Aurela, M., and Merilainen, J.: Low-molecular-weight dicarboxylic acids in an urban and rural atmosphere, J. Aerosol Sci., 31, 349362, 2000.

Kerminen, V. M., Teinila, K., Hillamo, R., and Makela, T.: Sizesegregated chemistry of particulate dicarboxylic acids in the Arctic atmosphere, Atmos. Env., 33, 2089-2100, 1999.

Limbeck, A., Kraxner, Y., and Puxbaum, H.: Gas to particle distribution of low molecular weight dicarboxylic acids at two different sites in central Europe (Austria), J. Aerosol Sci., 36, 9911005, 2005.

Marcolli, C., Gedamke, S., Peter, T., and Zobrist, B.: Efficiency of immersion mode ice nucleation on surrogates of mineral dust, Atmos. Chem. Phys., 7, 5081-5091, doi:10.5194/acp-7-50812007, 2007.

Mikhailov, E., Vlasenko, S., Martin, S. T., Koop, T., and Pöschl, U., Amorphous and crystalline aerosol particles interacting with water vapor: conceptual framework and experimental evidence for restructuring, phase transitions and kinetic limitations, Atmos. Chem. Phys., 9, 9491-9522, doi:10.5194/acp-9-9491-2009, 2009.

Mishchenko, M. I., Travis, L. D., and Mackowski, D. W.: T-matrix computations of light scattering by nonspherical particles: A review, J. Q. Spectrosc. Radiat. Transfer, 55, 535-575, 1996.

Möhler, O., Benz, S., Saathoff, H., Schnaiter, M., Wagner, R., Schneider, J., Walter, S., Ebert, V., and Wagner, S.: The effect of organic coating on the heterogeneous ice nucleation efficiency of mineral dust aerosols, Environ. Res. Letters, 3, 025007, doi:10.1088/1748-9326/3/2/025007, 2008.

Möhler, O., Büttner, S., Linke, C., Schnaiter, M., Saathoff, H., Stetzer, O., Wagner, R., Krämer, M., Mangold, A., Ebert, V., and Schurath, U.: Effect of Sulphuric Acid Coating on Heterogeneous Ice Nucleation by Soot Aerosol Particles, J. Geophys. Res. Atmos., 110, D11210, doi:10.1029/2004JD005169, 2005.

Möhler, O., Field, P. R., Connolly, P., Benz, S., Saathoff, H., Schnaiter, M., Wagner, R., Cotton, R., Krämer, M., Mangold, A., and Heymsfield, A. J.: Efficiency of the deposition mode ice nucleation on mineral dust particles, Atmos. Chem. Phys., 6, 3007-3021, doi:10.5194/acp-6-3007-2006, 2006.

Mossop, S. C.: Sublimation Nuclei, P. Phys. Soc. Lond. B, 69, 161164, 1956.

Murphy, D. M. and Koop, T.: Review of the vapour pressures of ice and supercooled water for atmospheric applications, Q. J. Roy. Meteorol. Soc., 131, 1539-1565, 2005.

Murray, B. J., Wilson, T. W., Dobbie, S., Cui, Z., Al-Jumur, S. M. 
R. K., Möhler, O., Schnaiter, M., Wagner, R., Benz, S., Niemand, M., Saathoff, H., Ebert, V., Wagner, S., and Kärcher, B.: Heterogeneous nucleation of ice particles on glassy aerosols under cirrus conditions, Nat. Geosci., 3, 233-237, 2010.

Omar, W. and Ulrich, J.: Solid liquid equilibrium, metastable zone, and nucleation parameters of the oxalic acid-water system, Cryst. Growth Des., 6, 1927-1930, 2006.

Parsons, M. T., Mak, J., Lipetz, S. R., and Bertram, A. K., Deliquescence of malonic, succinic, glutaric, and adipic acid particles, J. Geophys. Res. Atmos., 109, D06212, doi:10.1029/2003JD004075, 2004.

Peng, C., Chan, M. N., and Chan, C. K.: The hygroscopic properties of dicarboxylic and multifunctional acids: Measurements and UNIFAC predictions, Environ. Sci. Technol., 35, 4495-4501, 2001.

Peng, C. G. and Chan, C. K.: The water cycles of water-soluble organic salts of atmospheric importance, Atmos. Environ., 35, 1183-1192, 2001.

Prenni, A. J., DeMott, P. J., Kreidenweis, S. M., Sherman, D. E., Russell, L. M., and Ming, Y.: The effects of low molecular weight dicarboxylic acids on cloud formation, J. Phys. Chem. A, 105, 11240-11248, 2001.

Pruppacher, H. R. and Klett, J. D.: Microphysics of Clouds and Precipitation, Kluwer Acacdemic Publishers, Dordrecht, The Netherlands, 326-341, 1997.

Roberts, P. and Hallett, J.: A Laboratory Study of Ice Nucleating Properties of Some Mineral Particulates, Q. J. Roy. Meteorol. Soc., 94, 25-34, 1968.

Shilling, J. E., Fortin, T. J., and Tolbert, M. A.: Depositional ice nucleation on crystalline organic and inorganic solids, J. Geophys. Res. Atmos., 111, D12204, doi:10.1029/2005JD006664, 2006.

Torgesen, J. L. and Strassburger, J.: Growth of Oxalic Acid Single Crystals from Solution - Solvent Effects on Crystal Habit, Science, 146, 53-55, 1964.

Treuel, L., Schulze, S., Leisner, T., and Zellner, R., Deliquescence behaviour of single levitated ternary salt/carboxylic acid/water microdroplets, Faraday Discuss., 137, 265-278, 2008.

Vali, G.: Repeatability and randomness in heterogeneous freezing nucleation, Atmos. Chem. Phys., 8, 5017-5031, doi:10.5194/acp-8-5017-2008, 2008.

Villepin, J. D. and Novak, A.: Vibration-Spectra of Oxalic Acids.1. Infrared and Raman-Spectra of Beta-Phase of Some Acids, Spectrochim. Acta A, 34, 1009-1017, 1978a.

Villepin, J. D. and Novak, A.: Vibration-Spectra of Oxalic Acids.2. Infrared and Raman-Spectra of Alpha-Phase of Some Acids, Spectrochim. Acta A, 34, 1019-1024, 1978b.

Wagner, R., Benz, S., Bunz, H., Möhler, O., Saathoff, H., Schnaiter, M., Leisner, T., and Ebert, V.: Infrared Optical Constants of Highly Diluted Sulfuric Acid Solution Droplets at Cirrus Temperatures, J. Phys. Chem. A, 112, 11661-11676, 2008.
Wagner, R., Benz, S., Möhler, O., Saathoff, H., Schnaiter, M., and Schurath, U.: Mid-infrared extinction spectra and optical constants of supercooled water droplets, J. Phys. Chem. A, 109, 7099-7112, 2005a.

Wagner, R., Benz, S., Möhler, O., Saathoff, H., and Schurath, U.: Probing ice clouds by broadband mid-infrared extinction spectroscopy: case studies from ice nucleation experiments in the AIDA aerosol and cloud chamber, Atmos. Chem. Phys., 6, 47754800, doi:10.5194/acp-6-4775-2006, 2006.

Wagner, R., Linke, C., Naumann, K. H., Schnaiter, M., Vragel, M., Gangl, M., and Horvath, H.: A review of optical measurements at the aerosol and cloud chamber AIDA, J. Quant. Spectrosc. Radiat. Transfer, 110, 930-949, 2009.

Wagner, R., Möhler, O., Saathoff, H., Stetzer, O., and Schurath, U.: Infrared spectrum of nitric acid dihydrate - influence of particle shape, J. Phys. Chem. A, 109, 2572-2581, 2005b.

Wenger, M. and Bernstein, J.: Cocrystal design gone awry? A new dimorphic hydrate of oxalic acid, Mol. Pharm., 4, 355-359, 2007.

Yang, F., Chen, H., Wang, X. N., Yang, X., Du, J. F., and Chen, J. M.: Single particle mass spectrometry of oxalic acid in ambient aerosols in Shanghai: Mixing state and formation mechanism, Atmos. Environ., 43, 3876-3882, 2009.

Yao, X. H., Fang, M., and Chan, C. K.: Size distributions and formation of dicarboxylic acids in atmospheric particles, Atmos. Environ., 36, 2099-2107, 2002.

Zakharova, N. T. and Mishchenko, M. I.: Scattering properties of needlelike and platelike ice spheroids with moderate size parameters, Appl. Opt., 39, 5052-5057, 2000.

Zasetsky, A. Y., Khalizov, A. F., Earle, M. E., and Sloan, J. J.: Frequency Dependent Complex Refractive Indices of Supercooled Liquid Water and Ice Determined from Aerosol Extinction Spectra, J. Phys. Chem. A, 109, 2760-2764, 2005.

Zobrist, B., Marcolli, C., Koop, T., Luo, B. P., Murphy, D. M., Lohmann, U., Zardini, A. A., Krieger, U. K., Corti, T., Cziczo, D. J., Fueglistaler, S., Hudson, P. K., Thomson, D. S., and Peter, T.: Oxalic acid as a heterogeneous ice nucleus in the upper troposphere and its indirect aerosol effect, Atmos. Chem. Phys., 6, 3115-3129, doi:10.5194/acp-6-3115-2006, 2006.

Zobrist, B., Marcolli, C., Pedernera, D. A., and Koop, T.: Do atmospheric aerosols form glasses?, Atmos. Chem. Phys., 8, 52215244, doi:10.5194/acp-8-5221-2008, 2008.

Zuberi, B., Bertram, A. K., Koop, T., Molina, L. T., and Molina, M. J.: Heterogeneous freezing of aqueous particles induced by crystallized $\left(\mathrm{NH}_{4}\right)_{2} \mathrm{SO}_{4}$, ice, and letovicite, J. Phys. Chem. A, 105, 6458-6464, 2001. 